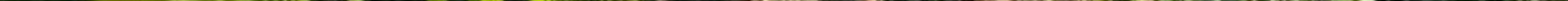




\section{L'image, la trace et la mémoire pratique. Pratiques sociales coutumières et les mémoires de la violence dans le Moyen Magdalena, Colombie}

\section{Artículo de investigación}

Recibido: 20 de septiembre de 2019

Aprobado: 15 de octubre de 2019

\section{Adrián Serna-Dimas}

Universidad Distrital Francisco José de Caldas, Colombia

aeserna@udistrital.edu.co

Cómo citar este artículo: Serna-Dimas, Adrián (2020). L'image, la trace et la mémoire pratique. Pratiques sociales coutumières et les mémoires de la violence dans le Moyen Magdalena, Colombie. Estudios Artísticos: revista de investigación creadora, 6(8) pp 120-146 DOI: https://doi. org/10.14483/25009311.15693

Platanera en la provincia del Gualivá, Cundinamarca. Archivo de investigación A. Serna-Dimas.

\section{(c) (i)}

https://creativecommons.org/licenses/by/4.0/deed.es
Image, trace et mémoire pratique. Pratiques sociales traditionnelles et souvenirs de la violence à Magdalena Medio, Colombie

\section{Résumé}

La crise du mythe entraîna une rupture qui jeta les choses à la nature, les mots comme signes à la science et les mots comme image vers l'art. Cette crise originale du mythe, sur laquelle la rationalité d'Occident est fondée, s'exprime dans les études de la mémoire sociale. La science privilégie la mémoire sociale qui reliée le monde social au motsigne (soulignant la facticité et la représentation par le concept contre l'illusion des images), tandis que l'art privilégia la mémoire imaginaire qui reliée le monde social à la mot-image (soulignant l'imagination contre le réductionnisme du concept). Les pratiques sociales, modes de habiter le monde social construit et de construire le monde social habité, forment une mémoire dans lesquelles les images ont gravés sous forme codifié les processus historiques survenus. Cette mémoire pratique permet d'identifier de manière transfigurée les impacts les plus profonds des contradictions et conflits, ainsi que ceux où la violence semble partie de la culture.

\section{Mots clés}

Image; trace; pratique sociale coutumière; mémoire pratique; mémoire idiosyncratique; modes de mémoire 


\section{Imagen, traza y memoria práctica. Prácticas sociales tradicionales y recuerdos de violencia en el Magdalena Medio, Colombia.}

\section{Resumen}

La crisis del mito entrañó una ruptura que arrojó las cosas a la naturaleza, las palabras a la ciencia y la imagen hacia el arte. Esta crisis original del mito, sobre la cual se estableció la racionalidad de Occidente, se expresa en los estudios de la memoria social. La ciencia privilegia la memoria social que une el mundo social a la palabra (resaltando la facticidad y la representación en el concepto contra la ilusión de las imágenes), mientras que el arte privilegia la memoria imaginaria que une el mundo social a la imagen (resaltando la imaginación contra el reduccionismo del concepto). Las prácticas sociales, modos de habitar el mundo social construido y de construir el mundo social habitado, forman unas memorias en las cuales las imágenes tienen grabadas bajo forma codificada los procesos históricos sucedidos. Esta memoria práctica permite identificar de manera transfigurada los impactos más profundos de las contradicciones y los conflictos, como aquellos donde la violencia parece parte de la cultura.

\section{Palabras clave}

Imagen; traza; práctica social consuetudinaria; memoria práctica; memoria idiosincrática, modos de la memoria.

\section{Image, Trace and Practical Memory. Traditional Social Practices and Memories of Violence in Magdalena Medio, Colombia}

\footnotetext{
Abstract

The crisis of myth entailed a break that threw things into nature, words to science and the image to art. This original crisis of myth, upon which the rationality of the West was established, is expressed in studies of social memory. Science privileges the social memory that joins the social world to the word (highlighting the factuality and representation found in concepts against the illusion of images), while art privileges the imaginary memory
}

that joins the social world to the image (highlighting the imagination against the reductionism of the concept). Social practices, those ways of inhabiting the built social world and of building the inhabited social world, form memories in which the images have engraved in themselves, in a coded form, the historical processes that have taken place. This practical memory allows to identify in a transfigured way the deepest impacts of contradictions and conflicts, such as those where violence seems part of the culture.

\section{Keywords}

Image; trace; customary social practice; practical memory; idiosyncratic memor; modes of memory

\section{Imagem, traço e memória prática. Práticas sociais tradicionais e lembranças de violência em Magdalena Medio, Colômbia}

\section{Resumo}

A crise do mito produziu uma ruptura que lançou as coisas na natureza, as palavras para a ciência e a imagem para a arte. Esta crise original do mito, sobre a qual se estabeleceu a racionalidade do Ocidente, se expressa nos estudos da memória social. A ciência privilegia a memória social que une o mundo social à palavra (ressaltando a facticidade e a representação no conceito contra a ilusão das imagens), enquanto que a arte privilegia a memória imaginária que une o mundo social à imagem (ressaltando a imaginação contra o reducionismo do conceito). As práticas sociais, modos de habitar o mundo social construído e de construir o mundo social habitado, formam umas memórias nas quais as imagens têm gravadas, sob forma codificada, os processos históricos sucedidos. Esta memória prática permite identificar, de maneira transfigurada, os impactos mais profundos das contradições e os conflitos, como aqueles onde a violência parece parte da cultura.

\section{Palavras-chave}

Imagem; traço; prática social consuetudinária; memória prática; memória idiossincrática; modos da memória 


\section{Ruria kuchuspa iuiarispa llakispa kauasaikuna kai atun llagta Magdalena chagpi- Colombia}

\section{Maillallachiska}

lapa llakispa kawachinku imasami wañuku mailla mailla Nukanchipa Ilagta, rimaikunawa ruraikunaua nunakaku tukuikunata iuiachingapa. Imammi ruraspa kauasanakunchi chasallata kauangapa. Imami ruraspa kausanakunchi. Chasallata kauangapa ñugpasinama imami iukanchi ruranga tukuikunata aidachispa imasapas allilla iuiarispa ñugpamanda kilkakunataiachichingapa, sugkunata chasa tukuikuna iachasunchimi imasami kaska ñugpa iakikunaua kaugsai.

\section{Rimangapa Ministidukuna}

Kauai, kuchuspa rurai; practica social consuetudinaria; ñugpamandata kunaura kausai; memoria idiosincrática; sugpi sugpi iuiarispa

Le Magdalena est un long projet de la mer... (Buenahora, 1970, p. 332)

\section{Introduction}

La crise du mythe dans la tradition occidentale introduisit la dichotomie entre les choses (la nature) et les mots (le concept) ainsi que de la dichotomie entre les mots comme signes (pour la science) et les mots comme images (pour l'art). Ces dichotomies ne sont rien d'autre que la séparation de la science et la poésie, de ce que disent Adorno et Horkheimer: «La séparation précise de la science et de la poésie étend la division du travail au langage. En tant que signe, le mot passe à la science; en tant que son, en tant qu'image, en tant que le mot authentique, il est réparti entre les différents arts, sans pouvoir récupérer son addition, sa synesthésie ou son 'art total'. Le langage en tant que signe doit se résigner à être calcul ; pour connaître la nature, il faut renoncer à prétendre à être semblable à lui. Le langage en tant qu'image doit se résigner à être une copie ; pour être entièrement parti de la nature, il faut renoncer à prétendre la connaître » (Horkheimer et Adorno, 2010, p. 72).
Cet effondrement du mythe traverse les conceptions de la mémoire sociale dans la tradition occidentale. Le souvenir et l'oubli peuvent être affaire des sciences mais seulement sous la forme des signes extérieures, différés ou disparus des évènements passés, et ils peuvent être affaire des arts mais seulement sous la forme des images qu'imitent avec degrés de précision variable les événements sans pouvoir dire quelque chose sur eux : le signe parle des événements mais s'éloignant d'eux pour ne faire pas partie de sa nature et l'image conserve leur participation à la nature des événements mais au prix du silence -le drame de la victime qui ne peut pas parler des événements mais préserve, presque intacts, les images d'eux-.

L'effondrement du mythe entraîne aussi pour le monde social une tension entre ce qui est considéré comme établi o régulière avec ce qui est considéré anormal ou étrange: le mythe s'effondre parce qu'il ne peut pas faire l'absorption du événement émergent dans les systèmes existants, aussi parce qu'il ne peut pas faire que l'histoire soit subordonné subrepticement à la structure (LéviStrauss, 1962, p. 305). Dans ces circonstances, la violence symbolique qui a été imposée pour le mythe perd alors ses effets sur le monde social et le fait méconnaissable, en permettant l'exercice débordé de la violence physique sur tout ce qui peut paraître étrange ou non-familier. Ainsi, l'effondrement du mythe remet sur le tapis le rapport entre la culture et la violence, c'est-à-dire, les cadres admissibles et non-admissibles pour l'utilisation de la force brutale dans le monde social.

Les évidences de la crise structurelle du mythe restent enregistrées dans les pratiques sociales coutumières, en d'autres termes, dans toutes des activités humaines traditionnelles, leurs lieux d'exécution, leurs techniques et technologies et leurs produits. À cet égard, la géographie des pratiques sociales coutumières est l'horizon qui maintient unis les éléments disjoints pour la crise du mythe, est le dernier lieu où les choses et les mots comme signes et images - restent unis, mais pour alors elle ne soit pas qu'un territoire d'un monde social en ruines ou disparu. Cette géographie conserve les traces des signes aux images et, ce faisant, expose les éléments pour la reconstruction d'une mémoire sociale dans laquelle les images parlent. C'est le cas de la géographie des pratiques 


\section{LEYENDA}

Capital de la Repriblica

Capital de Departamento

Poblaciones

Postciones astronómicas tomatas

Ferrocarriles en explatacion

Terrocartzles en construccion

Aluras sobre el mar.

oficina de correo

Oficina Telegráfica

aficina de Telegrafla sin Hulo

Limite de Departamento

para csta carla se ha usado la Provección Sinusoidat

\section{PORMENORES GENERALES}

Cuadros de Distancias

Siguiendo la vaguada del rio

Bajo Magdalena

Bocas de ceniza Nombres

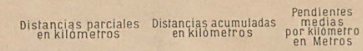

De Bocas de Cenza a Barranquilla

Barranquilla a sitio Nuevo

Remolino a Mata de Caria

- Trarim de cavia a Gudimaro

Greaimaro a salamin

Satamina a Piñón

Ei carro a calamar

Pedraza a Buenaris

Buenavista a Heredita

Heredia a Nervit

Tenerife a Jesus ded Rio

Jesús del Rlo a Zambrano

Tambrano a Tacamocho a Magangue

Hagangue a Barboza

Barboza a Boca Guamal

Boca Guamar a Barranea

anca a Banco

Puerta de Tamalameque a San Pediro.

Pegider a la Girria.

Reguar a la Grorma.

Gamarra a Bodega central

Bodega central a

Badillo a Tyjagual.

Vyagual a Boca Rosario
Boca Rosario a Paturia

Pocar hosarto a patasia

sar pablo a puerco minchies

Puerto Wizches a Rito Sagamoso

Burancabermeja a Boca Opón

Boca opón a Clucaur

Chucuri a Curare

-

Pernambuco a Puerto Berrio

- Garrapata a Nare.

Buenarista a Guariuma

Guarumo a Puerto Liérano

Puerto Liérwno a La. Doral
la Dorada a Rápidos
Rápidos a Honda

Honda

da

Alto Magdalena

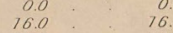

0.0
16.0
43.0

- Cambao a Beltrán

- Selirar a Ambarcma

Jaramillo a Guataque.

Guataqui a Nariño

Nariño a Gallinazo

Gallinazo a Rio coetro

Rio coello a Girardot

- Ricaurte a Santa lios

santa Rosa a Purificación.

Purificación a Marco

Nataquima a Barandillas

Barandillas a Aipe

Neiva al páramo del Letrero

Caños de Santa Marta

De Barranquita a Ciénaga (Cóndovas
Dique de Cartagena

Catamar

- Calamar a santa tricia

Santa Tucta a Arera

- sincerir a cartagena.

ique de Cartagena

Río San Jorge

Boca Perico

Soca perico a san Antonio

San Antonio a Jegui

- Mamón a chiquero.

- Briqueros a Boca sehe

Boca Guamal. 


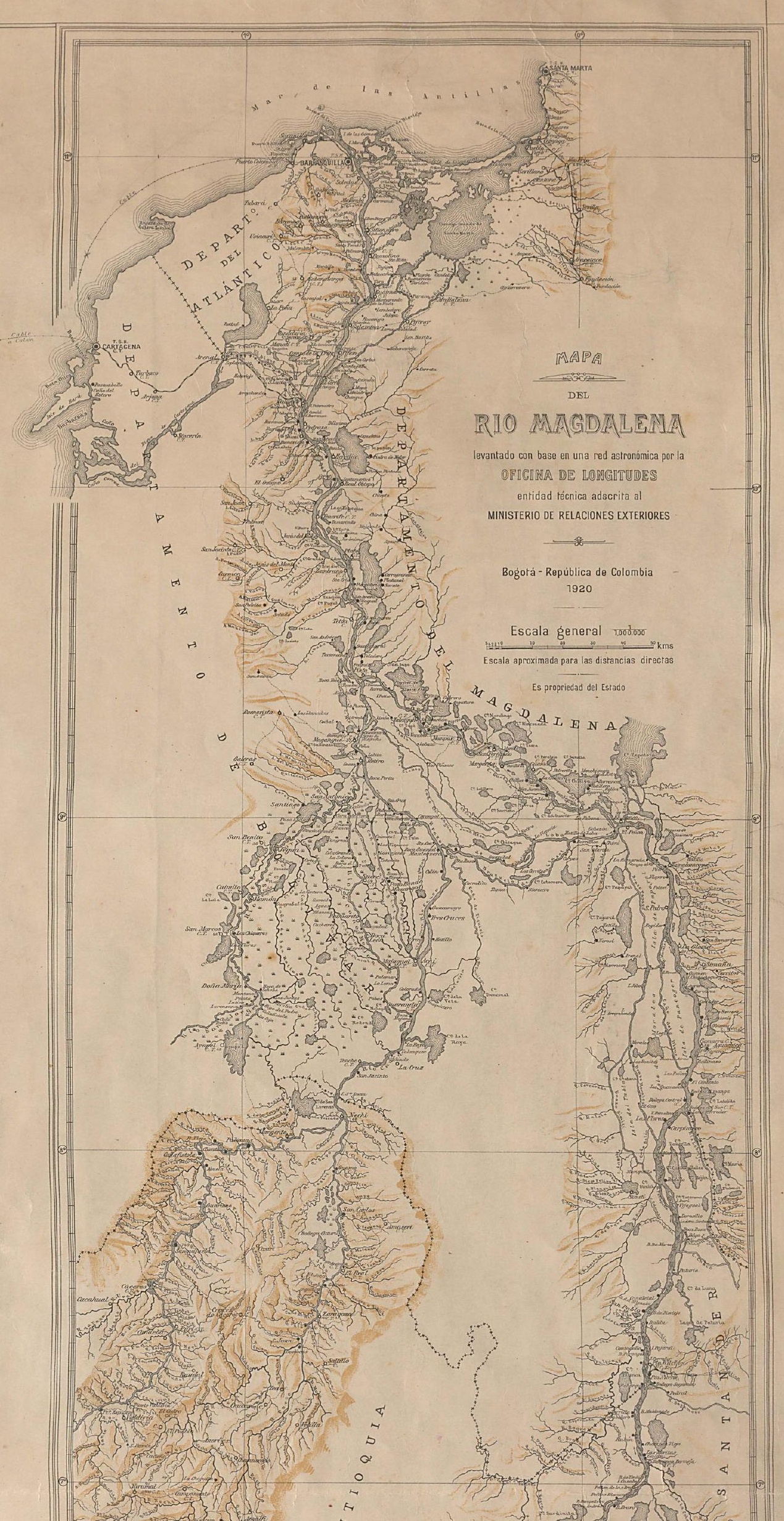


Boca Guamal.

ar a tres ances

0.0
27.5

- Guaranda a Rara

- Raya a Nechi

Necre a Margento.

- Patomas a canaristola

" Cañafistola a sarguryuela.

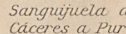

Purt a Puerto Valdina
Puerto Taldivia a Fuerto Espiritu Sunto

Caño Mojana

San Antonio

Sucre a Boca León

"Boca León a Majagual.

Nechi
De Nechi a Guamo

De Nechi a Guamo.

Sar carros a Puerto Andes

Puerto Andes a Job

- Angostura a Zaragoza

De El Banco a Belén

Bodega Central
De Bodega Central a Bi Choc

" Ér crocó a la ceiba.

De Bodega Sogamoso a Pedra

at.

Río Sogamoso

Río Cesar

0.0
37.5

F. C. de Cartagena

Ferpocarpiles
Via de una yasda:

Río Nechí

0.0
34.5
20.0
77.0
26.5

F. C. de Barranquilla

F. C. de Antioquia $\left\{\begin{array}{lr}\text { división del Nus. } & 109 \\ \text { división del Porce } & 64\end{array}\right\}$

F. C. de Amaga

F. C. del Tolima

C. de Girardot.

TI. C. de la Saba

C. del Sur
Velocidad

media del

De Mariquita a Soledad

Cable aereo

Transportes de Rio

Bajo Magdalena y afluentes.
Doce Companias disponen de 4 Buques de rapor servicios de pasajeros y carga relocidad the dia de 9 kitometros por hora en la subida y 77 en la bajada y capacidad total de 12,000 toneladas. Un Buque armado en guerra y varias Dragas del Gobierno.

Tres Compañias disponen de 12 Buques de vapor, servicios de pas ajeros y carga, velocidad media de skilómetros en la subida y 20 en la bajada; capacidad total de 3000 loneladas.

Una Draga del Gobierna.

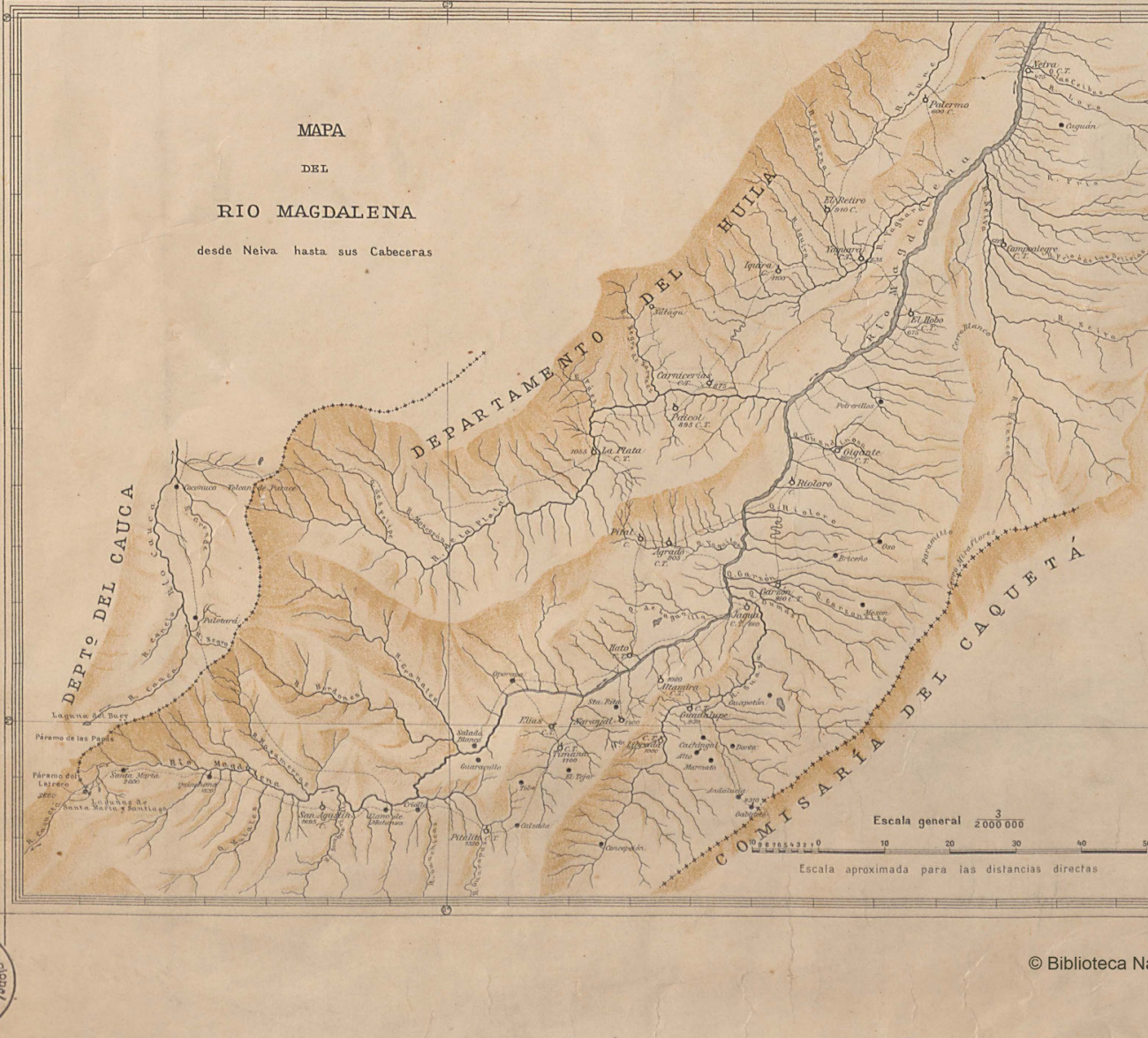




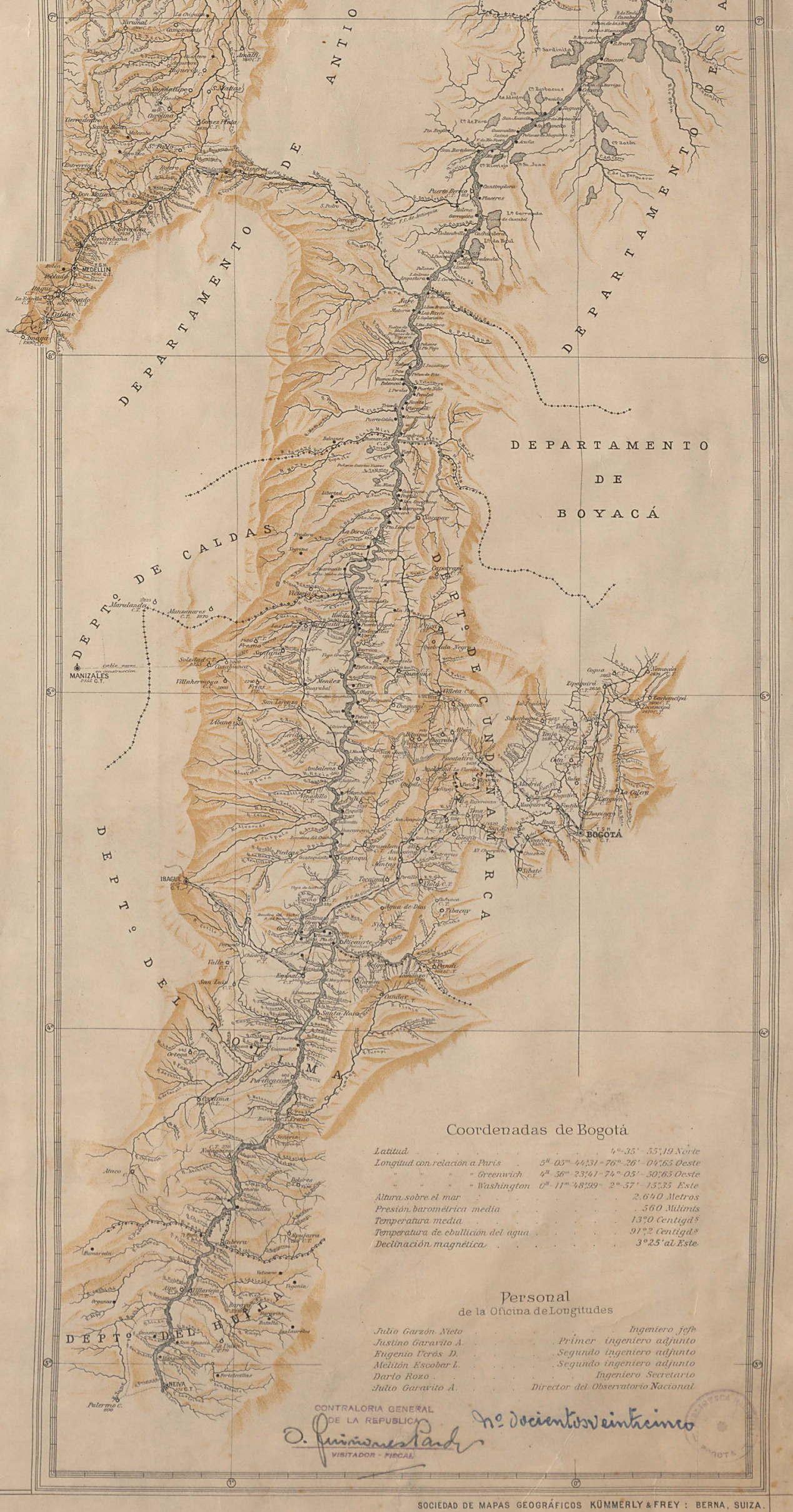

cional de Colombia 
sociales coutumières du fleuve Magdalena, qui conserve les traces d'un monde mythique qui a été abattu par siècles de violence jusqu'a présent. C'est géographie est requis pour entendre la mémoire sociale régionale ou idiosyncratique.

\section{Contexte geographique}

Le bassin du Magdalena, grand couloir formé par le cours du fleuve Magdalena, de sa source, au sud, dans la chaîne andine colombienne, jusqu'à son embouchure, au nord, dans la mer des Caraïbes, est divisé en trois grandes régions. La première, celle du Haut Magdalena, de sa source aux villes de Honda et Guaduas ; la seconde, celle du Moyen Magdalena, jusqu'à Morales et Gamarra ; et la troisième, du Bas Magdalena, jusqu'à son embouchure. Les deux premières sont encadrées par les contreforts des Andes et la troisième traverse marais et plaines côtières. Ces limites ne sont pas unanimes. Ce bassin n'inclut parfois que les localités situées en bordure du fleuve mais aussi parfois celles qui sont situées jusqu'à la partie basse ou moyenne des cordillères. De même, le Moyen Magdalena inclut parfois des localités au sud de Honda et Guaduas et en exclut celles qui sont au nord de Morales et Gamarra et dans d'autres cas sont exclues celles au sud de La Dorada et Puerto Salgar et inclues celles qui se trouvent autour de la dépression mompossine (de Mompos). Dans la présente recherche la région du Moyen Magdalena est délimitée comme suit : entre le confluent du Rio Bogotá au sud et celui du Rio Viejo au nord ; et entre l'altitude 1.800 $\mathrm{m}$ de la Cordillère orientale à l'est et l'altitude 1.800 $m$ de la Cordillère centrale à l'ouest (voir carte 1 ) (IGAC 2011).

Ainsi délimitée, on peut affirmer que la région du Moyen Magdalena est composée de cinq types de provinces, définies par des structures sociales, économiques, politiques et culturelles particulières. Les provinces riveraines, situées de part et d'autre du fleuve Magdalena, certaines comportant des localités (villes et villages) anciennes, datant des origines de la colonisation espagnole, d'autres des localités nées à l'époque de la régularisation de la navigation sur le fleuve vers la moitié du 19ème siècle. Les provinces du pétrole, entre la zone de marais (ciénagas) dans la province du Moyen Magdalena Bolivarense [département du
Bolivar] et le bassin inférieur du Rio Negro dans la province du Bas Magdalena Cundinamarqués [département du Cundinamarca], les unes comptant des localités anciennes, datant des origines de la colonisation espagnole, les autres des localités nées lors de la colonisation agraire à la fin du 19ème siècle, ou de la colonisation pétrolière dans la première moitié du 20 ème siècle. Les provinces des émeraudes, situées entre le bassin moyen et haut du Rio Carare dans la province de Vélez [département du Santander] et le bassin moyen et haut du Rio Negro dans la province de Rionegro [département du Cundinamarca], où coexistent des localités anciennes, remontant aux origines de la colonisation espagnole, et d'autres qui se sont formées au fil des siècles dans diverses circonstances, notamment les disputes pour le monopole des mines d'émeraudes. Les provinces de la canne à sucre, situées sur les versants moyens des deux cordillères, en particulier dans la cuvette du Rio Suárez [département du Santander], dans les provinces Oriente [Est] et Nordeste [Nord-est] dans I'Antioquia et les bassins du Rio Negro et du Rio Bogotá dans le Cundinamarca, avec des localités nées pour la plupart à l'époque coloniale. Les provinces de la frontière caféière, situées les unes sur le versant de la Cordillère centrale, avec des localités nées lors de la dernière avancée de la colonisation antioqueña entre 1880 et 1900, les autres sur le versant de la Cordillère orientale, avec des localités plus anciennes, remontant pour certaines aux origines de la colonisation espagnole (IGAC, 2011).

\section{La mémoire pratique et la mémoire idiosyncratique}

Cefte recherche eut pour objectif principal de clarifier quel rôle joua la culture des provinces de la région du Moyen Magdalena dans l'assimilation des contradictions, des conflits et des violences historiques résultants des rapports entre les gens et la nature, ainsi que des implications de cette assimilation sur la construction d'une philosophie de l'histoire sur laquelle a été construite une mémoire sociale des violences anciennes et plus récents. La recherche proposa un cadre théorique et méthodologique fondé sur une ethnosociologie des pratiques sociales coutumières des différentes provinces du Moyen Magdalena —une 
ethnosociologie qui repose sur l'objectivation participante. Bourdieu dit à propos:

...on n'a pas a choisir entre l'observation participante, immersion nécessairement fictive dans un milieu étranger, et l'objectivisme du "regard éloigné" d'un observateur qui reste aussi distant de lui-même que de son objet. L'objectivation participante se donne pour objet d'explorer, non "l'expérience vécue" du sujet connaissant, mais les conditions sociales de possibilité (donc les effets et les limites) de cette expérience et, plus précisément, de l'acte de objectivation. Elle vise à une objectivation du rapport subjectif à l'objet qui, loin d'aboutir à un subjectivisme relativiste et plus ou moins antiscientifique, est une condition de l'objectivité scientifique... (Bourdieu, 2008, p. 325) —

Cette ethnosociologie s'est engagé à élucider sur las surfaces des pratiques sociales coutumières de chaque province du Moyen Magdalena, les traces des diverses processus naturels, historiques, sociaux, culturels et politiques au long des siècles. Ces traces, par la capacité de la pratique de faire la dénégation de l'historicité, ne semblaient pas partie d'aucune histoire. Elles apparaissent couverts de la poussière, intégrées aux pratiques sociales, adaptées à leurs fonctions actuelles, dehors du temps. Ayant la ethnosociologie comme prémisse épistémologique l'histoire sociale, c'est-à-dire, l'interrogation de l'historicité qui reste inconscient au sein des pratiques sociales, peut alors dépoussiérer les traces et les réintégrer à l'histoire dans sa totalité:

Si les prétentions de connaissance systématique apparaissent de plus en plus velléitaires, ce n'est pas une raison pour abandonner l'idée de totalité. Bien au contraire, l'existence d'une articulation profonde susceptible de rendre compte des phénomènes superficiels se trouve réaffirmé au moment même où l'on récusé qu'une connaissance directe d'une telle articulation soit possible. Si la réalité est opaque, des zones privilégiées existent —traces, indices- qui permettent de la déchiffrer... (Ginzburg, 1989, pp. 289-290).

Ainsi, la pêche et la navigation dans les rivières et marécages, l'exploitation forestière dans les versants des cordillères, les différentes cultures de la terre, l'élevage du bétail sur les plaines chaudes ou l'extraction des mines ou de pétrole surgirent en des moments particulières et ils ont aussi été développés sous certains conditions historiques déterminées. Ces cadres historiques sont enregistrés de manière chiffrée sur la nature (le fleuve, la plaine, la montagne, la forêt), les corps humaines et animaux (l'anatomie, le mouvement, l'apparence physique), les techniques ou technologies (le bateau, le rame, I'hache, le machette, le sillon), les activités quotidiennes (semer, collecter, irriguer), les processus qui permettent l'apprentissage de ces activités (l'imitation, l'exemple, la discipline, l'éducation), les valeurs sociales régnantes (l'obéissance, la soumission, la rudesse), l'image du monde (ou weltanschauung) et, en fin de compte, l'ensemble des structures du monde social. C'est la trace la seule chose visible de cet enregistrement symbolique de l'histoire sous la forme de la nature que l'ethnosociologie peut suivre aux profondeurs du monde social.

Désormais, les pratiques sociales coutumières du Moyen Magdalena, ayant la capacité de convertir I'histoire en nature, peuvent ainsi également imposer des identités sociales et culturelles des gens des provinces, ce qu'on appelle l'idiosyncrasie. L'idiosyncrasie est l'identité qui surgit de la naturalisation des conditions historiques, d'autant plus forte qu'elle soit le produit des pratiques sociales coutumières immuables ou avec des changements mineurs ou aussi le produit des pratiques sociales coutumières enfermées dans territoires enclavés ou sans liens étroits avec les autres territoires. Les modes pratiques d'habiter le monde social sont l'indicatif de l'identité avec lui, c'est-à-dire, de l'incorporation de l'histoire en soumettant à les pratiques sociales établies. Plus une territoire est enfermée ou plus ses pratiques sociales sont non modifiables, plus l'identité est exaltée dans la singularité des corps.

Mais le Moyen Magdalena est aussi le produit d'une histoire des profondes contradictions, conflits et violences qui sont enregistrés comme une partie substantielle des pratiques sociales coutumières, en d'autres termes, comme s'ils provenaient de la nature. Ainsi, dès las formes d'occupation du territoire pour les peuples indigènes, en passant pour des modes d'imposition des puissances étrangères —comme l'Espagne, l'Allemagne et les États-Unis-, jusqu'à des formes d'exploitation paysanne des derniers siècles, il y a un ensemble de contradictions, conflits et violences superposés qui ont colonisé subrepticement les pratiques 
sociales coutumières. Le vigueur formidable de la nature, l'effort considérable au travail, la limitation ou l'impuissance des techniques et technologies, la souffrance pour obtenir le pan quotidien, le caractère hasardeux des pauvretés et des richesses, la violence elle-même, ils semblaient une destin pour compte de la nature que le résultat de l'histoire humaine -marquée par la présence de trois empires et une faible république-. L'idiosyncrasie même admet inaperçue ces vicissitudes qui, ainsi, deviennent partie de l'identité des individus et des provinces mais édulcorées sous la forme du patrimoine culturel.

Cette naturalisation des différentes couches historiques superposées peut être dévêlée avec la excavation de ce monde social, à la manière de Benjamin:

La langue nous indique sans malentendu que la mémoire n'est pas un instrument pour connaître le passé, mais uniquement le médium. C'est le médium du vécu comme la terre est le médium où sont ensevelies les anciennes villes. Qui tente de s'approcher de son propre passé enseveli doit faire comme un homme qui fouille. II ne doit surtout pas craindre de revenir sans cesse à un seul et même état de choses à le disperser comme on disperse de la terre, à le retourner comme on retourne sur la terre. Les "états de choses" ne sont rien de plus que des couches qui ne livrent qu'après une exploration méticuleuse ce qui justifie ces fouilles. C'est-à-dire les images, qui, arrachées à tout contexte antérieur, sont pour notre regard ultérieur des joyaux en habits sobres de notre connaissance postérieur, comme torses brisés dans la galerie du collectionneur. Et il est à coup sûr utile, lors de fouilles, de procéder selon des plans. Mais tout aussi indispensable est le coup de bêche précautionneux et tâtonnant dans l'obscur royaume de la terre. E† il se frustre du meilleur, celui qui fait seulement l'inventaire des objets mis au jour et n'est pas capable de montrer dans le sol actuel l'endroit où l'ancien était conservé. Ainsi les véritables souvenirs doivent-ils moins procéder du rapport que désigner exactement l'endroit où le chercheur a mis la main sur eux. Donc, stricto sensu, le véritable souvenir doit donc, sur un mode épique et rhapsodique, donner en même temps une image de celui qui se souvient, de même qu'un bon rapport archéologique ne doit pas seulement indiquer les couches d'où proviennent les découvertes mais aussi et surtout celles qu'il a fallu traverser auparavant » (Benjamin, ¿1932? / 2010, p. 350)
L'excavation des pratiques sociales coutumières permet d'interroger la mémoire pratique, c'est-àdire, la mémoire orchestrée à travers des pratiques sociales avec leur capacité d'historisation, ahistorisation et déshistorisation des traces du monde social. Cette mémoire est l'origine des enracinements au territoire, le mode pour l'apprentissage des tâches habituelles, la série originale pour l'appropriation des événements récurrents ainsi que les événements imprévus et, enfin, la base des modes de souvenir et d'oublier des gens dans la vie quotidienne. La mémoire pratique, au même temps mémoire idiosyncratique, peut être fouillée pour identifier l'assimilation des contradictions, des conflits et des violences opérée pour la culture à travers de différentes formes symboliques, étant ainsi la source des anamnèses, amnésies et paramnésies sociales - la mémoire pratique est une mémoire d'immanences que ne se présente jamais comme mémoire: c'est une mémoire destinée à transformer le souvenir en l'oubli en tant que réalisation d'un acte de sublimation-.

Cette mémoire pratique permet de restituer le rapport entre la chose et le mot ainsi qu'entre le mot comme signe et le mot comme image en reprenant le monde social sous ses formes mythiques ou sous ses formes ruinées de la mythologie. Pour ce faire, il convient d'entendre que, pour la mémoire pratique, le signe devient un intermédiaire entre l'image et le concept:

\section{...Comme l'image, le signe est un être concret, mais il res-} semble au concept pour son pouvoir référentiel: I'un et l'autre ne se rapportent pas exclusivement à eux-mêmes, ils peuvent remplacer autre chose que soi. Toutefois, le concept possède à cet égard une capacité illimitée, tandis que celle du signe est limitée... » (Lévi-Strauss 1962: pp. 28-29). La vérité de la pratique ne serait pas réduite à la possibilité du mot de représenter la chose ou à la capacité du signe de donner sens aux images, mais à la nature du signe de devenir être concrète ou de la image de devenir forme qui parle, c'est-à-dire, une relation solidaire où l'image bien peut être permutable avec le mot et vice-versa: « L'image ne peut pas être idée, mais elle peut jouer le rôle de signe, ou, plus exactement, cohabiter avec l'idée dans un signe; et, si l'idée n'est pas encore là, respecter sa place future et en faire apparaître négativement les contours. L'image est figée, liée de façon univoque à l'acte de conscience qui l'accompagne; mais le signe, et l'image devenue signifiante, s'ils sont encore sans compréhension, c'est-à-dire 


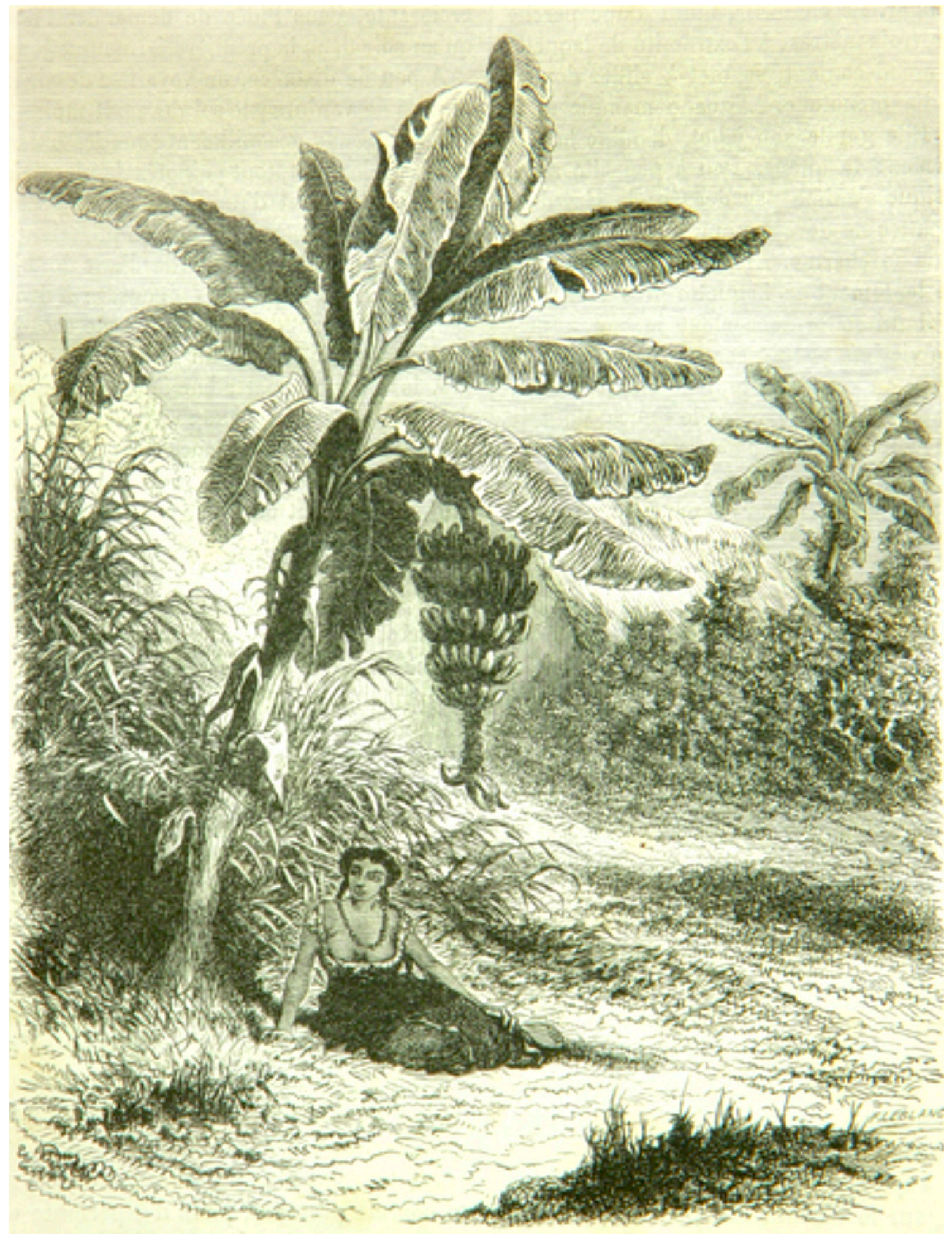

Imagen 2. L'étude de la bananeraie (Musa paradisiaca), A. Neuville y Ch. Saffray (Saffray, 1869, p. 100). 
sans rapports simultanés et théoriquement illimites avec d'autres êtres du même type — ce qui est le privilège du concept- sont déjà permutables, c'est-à-dire susceptibles d'entretenir des rapports successifs avec d'autres êtres, bien qu'en nombre limité, et... à la condition de former toujours un système où une modification affectant un élément intéressera automatiquement tous les autres: sur ce plan, l'extension et la compréhension des logiciens existent, non comme deux aspects distincts et complémentaires, mais comme réalité solidaire... (Lévi-Strauss 1962, p. 31)

Alors, il s'agirait d'une mémoire qui pourrait mettre en lumière la vérité de la pratique, une vérité qui sans épuiser la vérité de la science (historique, sociologique ou anthropologique), peut néanmoins être le sujet d'une science de la pratique -il convient de rappeler que Durkheim, Mauss et Lévi-Strauss ont pu inaugurer une science du mythe fondé non sur la science mais sur la connaissance mythique (Bourdieu, 1980 p. 13) -. La mémoire pratique n'opère pas comme la science, c'est-àdire, en faisant la distinction entre des événements et des structures, mais comme la pensée mythique et le bricolage:

...le propre de la pensée mythique, comme du bricolage sur le plan pratique, est d'élaborer des ensembles structurés, non pas directement avec d'autres ensembles structurés, mais en utilisant des résidus et des débris d'événements : "odds and ends", dirait l'anglais, ou, en français, des bribes et des morceaux, témoins fossiles de l'histoire d'un individu ou d'une société. En un sens, le rapport entre diachronie et synchronie est donc inversé: la pensée mythique, cette bricoleuse, élabore des structures en agençant des événements, ou plutôt des résidus d'événements, alors que la science, "en marche" du seul fait qu'elle instaure, crée, sous forme d'événements, ses moyens et ses résultats, grâce à des structures qui fabrique sans trêve et qui sont ses hypothèses et théories... » (Lévi-Strauss, 1962, pp. 32-33)

La géographie des pratiques sociales coutumières soumise à des effets de la violence laisse exposé un ensemble des décombres où la systématicité est garantie pour le paysage -le paysage naquit avec le mythe ou il survit grâce à la mythologie-. Ainsi, les pratiques sociales coutumières habitent le monde social en créant une géographie que l'on ne peut pas réduire au topos mais qui elle doit se comprendre en termes de chôra — «...de l'explication et de la description physiques au postulat et à la définition de la réalité sensible... » Aussi, [du] lieu physique relatif [à] la propriété ontologique qui fonde cette localisation...» (Pradeau signalé par Berque, 2009, p. 31). La chôra s'est le paysage du mythe et de la mythologie, «... c'est ce que disent les choses mêmes dans le milieu qui est le leur: l'entant-que de toute existence; et je le dirais plus: de l'existence... » (Berque, 2009, pp. 39-40). Cette relation entre le paysage, le mythe et la mythologie, qui permet la permutabilité de l'image et le concept, ouvre la possibilité à l'art de se constituer en la voie pour l'accès à la mémoire pratique -le paysage permet que la connaissance géographique soit une forme de l'art-. Lévi-Strauss a dit à propos de l'art:

... Les mythes nous apparaissent simultanément comme des systèmes de relations abstraites et comme des objets de contemplation esthétique : en effet, l'acte créateur qui engendre le mythe est symétrique et inverse de celui qu'on trouve à l'origine de l'œuvre d'art. Dans ce dernier cas, on part d'un ensemble formé d'un ou de plusieurs objets et d'un ou de plusieurs événements, auquel la création esthétique confère un caractère de totalité par la mise en évidence d'une structure commune. Le mythe suit le même parcours, mais dans l'autre sens: il utilise une structure pour produire un objet absolu offrant l'aspect d'un ensemble d'événements (puisque tout mythe raconte une histoire). L'art procède donc à partir d'un ensemble: (objet + événement) et va à la découverte de sa structure ; le mythe part d'une structure, au moyen de laquelle il entreprend la construction d'un ensemble: (objet + événement)... » (Lévi-Strauss, 196, p. 38)

Si l'éclairement de la mémoire pratique dépend des traces des processus historiques, sociaux, politiques et culturels enregistrées dans les pratiques sociales coutumières et ses géographies sous des formes des images, bien on peut dire qu'elle demande une science fondée sur l'art, c'est-à-dire, une connaissance que peut aller à les images en tant que produits matériels et symboliques avec ses propres formes de configuration, lesquelles néanmoins ils peuvent être interrogées en tant que produits des pratiques qui doivent sa pleine vérité aux conditions de possibilité qui offrent des contextes et des structures. La mémoire pratique du Moyen Magdalena a été gravée sur plusieurs pratiques sociales coutumières dont des contradictions, conflits et violences dorment dans des images emblématiques. 


\section{De I'histoire à la mèmoire du moyen Magdalena}

\subsection{L'histoire}

Dans l'ancien régime colonial, puis aux débuts de l'ordre républicain, le bassin moyen du Magdalena constituait une frontière intérieure. Ce tronçon du long couloir du fleuve était d'une extrême complexité à parcourir en raison de divers facteurs : le cours capricieux du fleuve, la présence d'animaux sauvages, les immenses marécages et la végétation exubérante, les versants abrupts des hautes montagnes, la quasi-absence de routes et localités importantes ; la zone faisait penser aux plus dangereuses forêts tropicales, à leurs atmosphères propices aux maladies mortelles; en outre, elle était connue pour abriter des peuples indigènes réputés sauvages et cruels (les indigènes caraïbes) et pour constituer le refuge de délinquants, de déserteurs et de militaires défaits à la guerre, ce qui renforçait encore son caractère de frontière infranchissable. À côté de cette image négative, le bassin était également considéré comme une prometteuse source de richesses, notamment la pêche et la navigation sur le fleuve, l'élevage de bétail dans les plaines alluviales, l'exploitation minière de l'or et de l'argent sur le versant de la Cordillère centrale et des émeraudes sur celui de la Cordillère orientale, les cultures de la canne à sucre et du cacao sur les versants chauds ou tempérés des deux cordillères, l'exploitation du bois dans les forêts du Carare et de l'Opón. Mais à cause de l'isolement géographique, la présence de gens incontrôlables ou dangereux et les difficultés matérielles pour l'exploitation des richesses naturelles, le bassin est resté jusqu'à la moitié du 19ème siècle un territoire délaissé, où seules subsistaient quelques localités d'enclave, dépourvues de toute institution officielle, avec des sociétés délabrées et des économies précaires. Aux yeux de certains observateurs de l'époque, le bassin du Moyen Magdalena n'était pas seulement la vaste zone frontière séparant la côte caribéenne de la montagne andine, il représentait également l'abîme à franchir pour laisser derrière soi le pays féodal de la Colonie et atteindre le pays moderne de la République — voir, par exemple, la relation du commissionné Manuel Ancízar (1853) —.

Dans la seconde moitié du 19ème siècle la région du Moyen Magdalena va acquérir une importance toute particulière dans le contexte d'une série de réformes de type libéral entreprises par les gouvernements nationaux de l'époque, visant notamment à dissoudre divers monopoles coloniaux, libérer la main-d'œuvre et la terre et impulser la colonisation des friches sur les terres basses. À travers ces initiatives, l'objectif des autorités est d'insérer le pays dans un système économique mondial en pleine expansion, requérant chaque jour davantage de matières premières du tropique. Les réformes mises en œuvre par les gouvernements et la demande accrue des marchés internationaux entraînent le placement de capitaux privés, l'appui aux premières colonisations paysannes et la création d'entreprises agricoles et minières sur les parties basses et moyennes des versants du bassin. Ces deux facteurs sont également déterminants pour la régularisation de la navigation sur le Magdalena, que ce soit sur de vieilles embarcations à voiles ou sur de modernes steamers. Cette avancée technique favorise la création d'une industrie navale et portuaire, qui à son tour va favoriser la naissance et l'essor de nouvelles exploitations commerciales, ainsi que le développement des modestes villages et hameaux riverains, l'intégration de provinces isolées, l'intensification du commerce, le lancement d'importants travaux publics comme la construction de routes et de voies ferrées. Mais bientôt les grandes réformes mises en $œ u v r e$ suscitent de vives tensions entre régions, pouvoirs, institutions et partis politiques du pays, lesquelles vont dégénérer en une succession de guerres civiles pendant près d'un demi-siècle. En particulier, la coexistence des anciennes structures féodales liées au servage et de nouvelles structures modernes liées au travail salarié, la présence simultanée d'une main-d'œuvre susceptible de recrutement et d'entrepreneurs dotés d'un pouvoir social, économique et politique, et la valeur stratégique de l'infrastructure navale et portuaire le long du Magdalena convertissent le bassin en une zone fondamentale de ces luttes intestines. Les localités voisines du fleuve et des rares voies terrestres existantes sont érigées en places fortes, tandis que celles plus éloignées vont abriter l'arrière-garde des armées ou devenir l'ultime refuge des vaincus.

Après la dernière de ces guerres civiles, connue sous le nom de Guerre des Mille Jours (1899-1902), le bassin du Moyen Magdalena va retrouver tout son dynamisme, lié principalement à l'expansion 
de l'économie caféière sur les versants andins, aux premières explorations et exploitations pétrolières au creux des forêts vierges, et à l'essor des industries navales et ferroviaires autour du fleuve. Il en résulte que les petites localités riveraines se transforment en d'importantes cités portuaires et que différents projets de construction de voies terrestres et ferrées sont mis en chantier ou relancés entre les principales villes dans la zone andine et la vallée du Magdalena. Mais à nouveau ce dynamisme va être source de fortes tensions dans le bassin. Dès la fin des années 1910 une paysannerie de plus en plus sensible aux injustices commises par les institutions traditionnelles, en particulier les haciendas, et un prolétariat alors en formation, disposé à affronter les entreprises nationales et étrangères dont l'activité est l'exploitation de diverses ressources naturelles, convertissent le bassin moyen du fleuve en une zone d'intenses mobilisations sociales, d'où émergeront les premières grandes organisations syndicales du pays. La réponse habituelle aux mobilisations de paysans et d'ouvriers est une répression brutale, orchestrée par les entrepreneurs et les autorités de l'époque. Dans ces circonstances la région devient le principal bastion des idées libérales, socialistes et communistes dans le pays, et c'est avec enthousiasme que ses habitants accueilleront la fin de l'Hégémonie conservatrice et la mise en place de la République libérale au début des années 1930 (Archila, 1991 ; Murillo et al., 1993 ; Vega, 2002 y 2002a ; Solano, 2003 ; Vega, Nuñez et Pereira, 2009).

Mais très vite, dans la même décennie, les auspices favorables sous lesquels ont débuté les gouvernements libéraux disparaissent. Les représailles perpétrées par les libéraux à l'encontre des conservateurs, en réaction à la répression gouvernementale subie durant des décennies dans différentes provinces, les demandes insatisfaites d'une paysannerie de mieux en mieux organisée, et l'aggravation des contradictions dans les industries navales, portuaires et minières ravivent les vieilles tensions dans la région. Ces tensions vont aller s'exacerbant dans un contexte de croissante pugnacité politique au niveau national, lié aux tentatives de la République libérale de mettre en œuvre une série de réformes visant, notamment, à garantir la fonction sociale de la terre, consacrer divers droits civils, politiques, sociaux et économiques élémentaires et imposer des schémas d'imposition fiscale modernes, toutes mesures qui provoquent la réaction furieuse des secteurs sociaux, factions et partis politiques adverses qui y voient une dangereuse avancée du libéralisme et du communisme. La pugnacité politique dégénère bientôt en actes de violence systématique entre libéraux et conservateurs, ces actes prennent une tournure brutale lors du retour des conservateurs au pouvoir au milieu des années quarante. Cette violence partisane, mieux connue comme "la Première Violence", ou simplement "la Violence", est particulièrement intense dans le bassin du Moyen Magdalena en raison de trois facteurs : certaines localités de la région ont une tradition ancienne de militance armée, remontant à la Guerre des Mille Jours, il existe dans certaines provinces une sorte de parité instable entre libéraux et conservateurs, et l'environnement naturel régional est propice à l'action des guérillas de l'un et l'autre bords, les plus emblématiques étant les bandes commandées par Rafael Rangel dans le Carare et Saúl Fajardo dans le Rio Negro (Vargas, 1992 ; Murillo et al., 1993).

À début des années cinquante le gouvernement conservateur est renversé par un coup d'État militaire. Celui-ci est accueilli favorablement dans divers secteurs sociaux, économiques et politiques du pays qui y voient une solution appropriée pour mettre un terme à la violence prédominante. La dictature militaire lance un plan de pacification nationale, comprenant un volet militaire : la démobilisation des guérillas partisanes dans le bassin du Moyen Magdalena, et un volet économico-social : colonisation planifiée, incitants à l'agriculture et I'industrie minière, construction de voies terrestres et ferroviaires. Dès les premiers programmes lancés à la fin des années 1940, dans le cadre des "politiques pour le développement", le bassin du Moyen Magdalena est considéré comme une zone d'intervention prioritaire. Mais très vite la gestion de la dictature militaire va se détériorer, les grands projets lancés dans la région sont démantelés, la violence officielle ressurgit, en particulier dans les localités et les provinces reconnues comme étant des bastions libéraux. Compte tenu de l'opposition croissante au gouvernement militaire dans le pays, les deux partis traditionnels négocient et s'accordent sur un pacte qui prévoit la cessation de la violence partisane, l'imposition d'un régime de parité dans l'administration publique, l'alternance 
dans l'exercice du pouvoir, et le départ du dictateur. Ce départ se produit en 1957. Le nouveau régime, appelé le Front national, poursuit le plan de pacification nationale lancé par le gouvernement militaire. II doit faire face dans tout le pays à un phénomène de bandolerismo (bandes armées), particulièrement actif dans certaines régions, notamment les provinces du bassin du Moyen Magdalena. Pour la plupart, les bandoleros sont des survivants des anciennes guérillas partisanes, devenus le bras armé des pouvoirs locaux dans plusieurs provinces ou localités ; certains sont considérés comme d'authentiques héros populaires, le plus fameux d'entre eux dans cette région étant sans aucun doute Efraín González (Sánchez et Meertens, 1983 ; Vargas, 1992 ; Murillo et al., 1993).

Le Front national va susciter la résistance de divers secteurs de la société qui le considèrent comme un pacte entre les vieilles élites politiques, visant non pas à résoudre les contradictions à l'origine des violences qui ont déchiré le pays, mais simplement à garantir une répartition clientéliste de I'État. La résistance au nouveau régime est le fait d'une dissidence du Parti libéral, de différentes organisations de gauche, notamment le Parti communiste, et d'une base sociale sympathisante du gouvernement militaire déchu et qui s'est organisée en un mouvement politique de caractère populaire nationaliste (ANAPO). Ces organisations politiques d'opposition sont particulièrement bien implantées dans le bassin du Moyen Magdalena : la faction libérale dissidente parce qu'elle représente la continuité d'une longue tradition de libéralisme contestataire, avec une saga quasi centenaire de caudillos; les organisations de gauche parce qu'elles représentent la continuité d'une tradition de mobilisation sociale qui remonte aux années vingt ; l'organisation populaire nationaliste parce qu'elle représente le gouvernement militaire dont la mémoire est vivace et positive dans certaines provinces, les unes majoritairement conservatrices, les autres ayant bénéficié des programmes de colonisation, de travaux publics et de bienfaisance. Mais surtout, ces organisations politiques trouvent un écho dans une région qui depuis les années 1940 traverse une crise généralisée à cause de l'épuisement du fleuve, lequel a entraîné le déclin des industries navales et portuaires, la contraction de nombreuses exploitations agricoles et minières, la dissolution de plusieurs organisations sociales, la précarisation de certaines localités et l'urbanisation désordonnée d'autres, et une aggravation des conflits sociaux liés à la terre et au travail. Plus les populations du bassin du Moyen Magdalena adhèrent aux organisations politiques opposées au Front national, et plus les autorités nationales délaissent la région, ce qui crée les conditions pour qu'elle abrite une insurrection de gauche naissante. Dans les premiers temps il s'agit d'une présence acceptée, soutenue et célébrée par la majeure partie de la population civile, principalement parce qu'elle constitue la seule garantie d'ordre et sécurité dans une région abandonnée à son sort, où les actes de délinquance en tout genre sont courants (Vargas, 1992 ; Murillo et al., 1993).

Dans les années soixante certains gouvernements nationaux vont tenter d'apporter une réponse aux conflits agraires et aux graves difficultés de I'urbanisation dans le pays en proposant, entre autres, une réforme agraire, mais celle-ci est immédiatement rejetée par les vieilles élites politiques. Dans la population ce rejet renforce l'idée que le Front national est un pacte qui tourne le dos aux nécessités réelles du pays, ce qui aggrave encore le malaise social dans les régions en souffrance comme le bassin du Moyen Magdalena. Concernant celui-ci, la persistance de la mobilisation paysanne exigeant des terres face à l'immuable et intraitable régime des haciendas, l'urbanisation chaotique des petites localités incapables de garantir les droits élémentaires des gens, la présence de guérillas communistes bien acceptées par la population, et le risque d'affectation d'une activité économique fondamentale comme l'exploitation pétrolière conduisent les autorités nationales à déclarer la région objectif prioritaire de la Doctrine de Sécurité nationale, qui est l'une des stratégies d'intervention anticommuniste des États-Unis durant la Guerre froide. Dans ce contexte sont mises en place la progressive militarisation de la région et, dans certaines provinces, l'imposition des mesures d'exception propres de l'état de siège : “carnetización” des habitants (enregistrement et obligation de porter en permanence le document d'identification), blocus alimentaires, détentions arbitraires, tortures, assassinats et disparitions forcées. On n'hésite pas à faire appel aux milices de justice privée utilisées depuis le début des années soixante par les multinationales pétrolières. Face à la croissante intervention militaire 
dans la région, la réponse des guérillas de gauche est l'augmentation des contrôles sur la population civile et des contributions de celle-ci, avec comme conséquence une détérioration des relations entre les insurgés et les bases paysannes (Vargas, 1992 ; Murillo et al., 1993 ; Alonso, 1997).

La situation se fait plus critique encore à la fin des années soixante-dix lorsque les narcotrafiquants investissent la région pour y développer leurs activités. Pour le très puissant Cartel de Medellin, résolu à se substituer à l'État ou à s'imposer comme un État autonome, le Moyen Magdalena comporte de multiples atouts : c'est une région enclavée au centre du pays, équidistante des principales villes de la Côte et de la zone andine, avec une disponibilité de vastes extensions de terre à bas prix, une population appauvrie ou dans la misère, une faible présence d'autorités civiles et militaires dans plusieurs provinces. Dans le Moyen Magdalena les narcotrafiquants trouvent un endroit propice pour introduire les cultures de coca et installer des laboratoires cocaleros ou "cuisines" (lieux pour la transformation de la feuille de coca) dans les provinces les plus reculées, pour blanchir les capitaux illicites en acquérant des terres agricoles et d'élevage dans les provinces prospères, pour s'infiltrer dans la classe dirigeante locale et régionale, et pour instaurer une vaste zone de sécurité conditionnée afin de faire face aux guérillas de gauche, aux cartels de la drogue rivaux et, finalement, à l'action de l'État colombien qui, sous la pression des agences anti-narcotiques américaines, se décide à réagir. À partir de la décennie 1980 les narcos font alliance avec les hacendados (propriétaires d'haciendas), les esmeralderos (exploitants ou négociants d'émeraudes), les éleveurs, les entrepreneurs, les militaires, les quelques prêtres et les politiciens de la région pour établir leur domination sur celle-ci. Ils y introduisent leur propre modèle de guerre anticommuniste et, avec leurs "escadrons de la mort", intensifient les agressions contre la large base sociale liée aux différentes organisations politiques de la région, en particulier contre les membres du parti communiste. De la sorte, la présence du narcotrafic va convertir les vieilles disputes de paysans pour la terre en une confrontation de milices à gages dépourvues d'idéologie, impliquées dans une "guerre sale", une violence effrénée fondée sur la propagation de rumeurs, l'accusation et la dénonciation indiscriminées, la menace systématique, l'assassinat barbare, le massacre de population civile. Ces escadrons de la mort sont à l'origine des groupes paramilitaires qui dans la seconde moitié des années quatre-vingt-dix atteindront la domination quasi-totale de la région, tout en s'étendant à d'autres régions, puis à l'ensemble du pays, menant ainsi la Colombie à des niveaux de catastrophe humanitaire (Vargas, 1992 ; Murillo et al., 1993 ; Alonso, 1997 ; Archila, Bolívar et al., 2006).

\subsection{La mémoire (pratique)}

Les vingt dernières années du siècle passé, les vieux mondes primordiaux du bassin du Moyen Magdalena arrivèrent à leur fin. Les origines de ces mondes remontaient aux temps coloniaux, modelés dans leurs traits les plus primitifs et dans leurs pratiques les plus élémentaires dans la bananeraie riveraine (el platanal), une zone isolée au milieu d'une forêt magnifique où quelques rares hommes et femmes construisirent leur vie sans prétendre soumettre une nature omnipotente. Dans ces mondes des forces naturelles s'entrecroisaient avec des forces humaines: la fleuve, la plaine, la montagne et la forêt présentent des caractères humaines ainsi que le pêcheur, le navigateur, le semeur ou le scieur de bois se comportent comme parti de la nature. C'est le paradis originel sur le Moyen Magdalena ayant pour mode d'expression le vers, la poésie, la chanson populaire et le conte - ce dernier l'agonie du mythe-.

Par la suite le monde primordial dut connaître les premières cultures commerciales, les travailleurs qui venaient pour vivre d'un salaire, firent prospérer les premiers villages, donnèrent vie aux ports, et qui, enfin, entreprirent l'œuvre civilisatrice. Le développement des cultures commerciales entraîna la soumission de la main d'œuvre, la délimitation des terres et l'imposition de la propriété privée, l'introduction de techniques et technologies pour la maximisation de la production et, enfin, la prétention de l'accumulation capitaliste. Les nouvelles circonstances impliquant diverses tragédies humaines: la dissolution des familles, la désobéissance aux pères, la fugue du foyer, la quête de l'amour romantique, la perte des amoraux, tout ceci raconté par le roman.

Mais il s'agissait d'une modernisation interne à l'intérieur d'un pays périphérique exposé aux turbulences du capitalisme industriel mondial. Les 


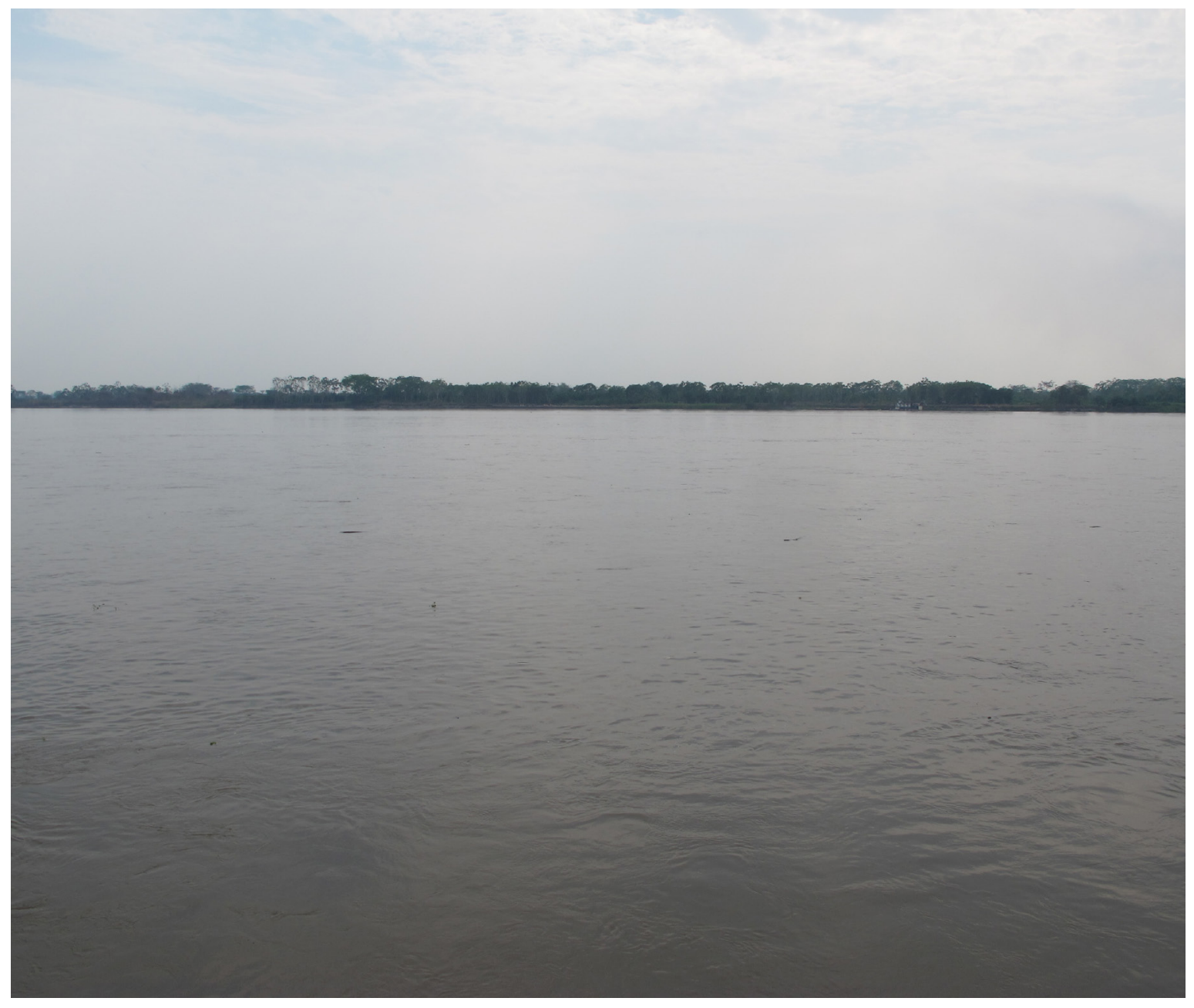

Imagen 3. Les rives du Magdalena sur Yondó (Antioquia).

changements de l'offre et la demande mèneraient aussi à changements des cultures commerciales de la terre chaude du fleuve Magdalena: chaque culture de la terre eut un période de croissance économique suivi pour un période de décroissance - nombreuses fois jusqu'à l'extinction de la production-. La croissance s'accompagnait de l'espoir des richesses mais aussi avec le déchainement des violences; la décroissance approfondissait des violences ainsi que la prolifération de la pauvreté. La situation n'a pas varié avec l'industrialisation des mines ou l'apparition de l'exploitation du pétrole. Les tragédies humaines sont indissociables des crises de la production économique, des perturbations sociales, des tensions politiques et des contradictions culturelles. Á la fin, l'effondrement des mondes vierges primordiaux ainsi que des mondes de cultures, mines et industries laissent un répertoire des images de diverses conjonctures historiques qui peuvent survivre mais sous la forme de objets culturels. Ces objets conservent partiellement leurs histoires originales chiffrées, avec toutes ces contradictions, conflits et tragédies que viennent chez nous sous la forme d'espèces naufragées.

Effectivement, depuis l'effondrement des mondes vierges primordiaux survécurent quelques espèces naufragées dans ce projet maritime que représentait le Rio Magdalena : les emblèmes féminins 
incarnés dans les vierges, les sorcières et les reines, d'une part, les épouvantails du fleuve, de la forêt et de la montagne de l'autre et encore les fantômes de l'indien d'antan. Ces espèces naufragées chargées de la violence mythologique qui les fit possibles, paraissaient toutefois purgées de toute violence, revêtues comme objets patrimoniaux, comme des questions de bonté du génie humain, et même comme des références de paix et de pacification. La négation de la violence au nom de la mythologie était une façon de disculper la culture de la violence.

\section{Trois ensembles d'images}

La caractérisation des activités quotidiennes comme les pratiques sociales coutumières qui structuraient, et étaient structurées par, des mondes sociaux particuliers, montra que la région du Moyen Magdalena possédait une histoire profonde qui impliquait, mais aussi transcendait, les récits récurrents dépendants du mode de pensée des régimes politiques, du devenir des mobilisations et manifestations sociales, de l'arrivée des guerres et violences de l'indépendance à nos jours. C'est une longue histoire de structures superposées dans le temps. Les plus anciennes ayant pour base les bananeraies, l'éden originel ou le paradis tropical du bassin du Moyen Magdalena, si souvent inconnu ou ignoré, mais de toute manière persistant jusqu'à aujourd'hui. Viennent ensuite les structures basées sur les cultures et les industries comme le tabac ou le café, mais aussi comme les mines mécanisées ou les puits de pétrole, sujets préférés des études universitaire et scientifique, bien qu'elles soient considérées davantage comme des événements plus que des structures. Celles-ci fondées sur les cultures et les industries supposent une relation particulière entre l'homme et chaque environnement naturel et par là-même la typicité de certaines techniques et technologies, tout ce qui est à l'origine de ce qu'on appelle les idiosyncrasies de province. Ces structures basées sur les cultures et les industries ne sont pas autre chose que les mondes primordiaux, les formes quintessentielles du monde social, la bourgade essentielle où la culture et l'industrie ordonne et organise tant le monde naturel que le monde social. Les mondes primordiaux substituent la consistance mythique de la bananeraie par la mythologie des idiosyncrasies.
Ces mondes primordiaux furent ceux qui entrèrent en déclin dans la seconde moitié du siècle passé, dont l'une des dernières expressions fut précisément la culture de la coca.

L'écroulement des mondes primordiaux, l'effondrement des structures basées sur les cultures et les industries, a laissé des débris éparpillés dans les différentes provinces du Moyen Magdalena. Ces débris passent le plus souvent inaperçus car ils semblent très prosaïques, mais surtout parce qu'ils survivent dans leurs fonctions élémentaires : la bananeraie embourbée sur les bords du fleuve ou couverte par la poussière des chemins, le hamac raide et effiloché, les palissades en bambou qui imitent la forêt là où il n'y a que des prairies ou qui imitent la prairie où il n'y a que des forêts, les sentiers qui traversent les crêtes des montagnes ou qui descendent des cordillères, les techniques et les technologies obsolètes qui renoncent à disparaître ou dont on sait qu'elles survivront des siècles dans des zones oubliées -comme le mortier avec son pilon dans la cour ou le trapiche de sangre (moulin à traction animale pour la canne à sucre) avec son rythme lent et son bruit de vieille crécelle-. Les ruines des mondes primordiaux sont d'un caractère élémentaire, d'une simplicité affligeante, d'une telle rusticité qu'ils ne retiennent en rien l'attention de sciences sociales toujours plus hypnotisées par la sophistication des discours ou la profusion de métaphores étrangères à ce pays de paysans qui furent nos ancêtres et nos parents-comme si les spécialistes de sciences sociales avaient perdu la trace de la bananeraie qui est à l'origine d'eux-mêmes-.

Avec ces débris sont également restées à la dérive des espèces naufragées : des entités fondamentales dans les mondes primordiaux qui, au milieu de l'effondrement, ont commencé à errer dans des structures sociales, politiques et culturelles étranges qui, bien qu'elles les aient accueillies parce que, des mondes dont elles provenaient, elles apportaient la force mythologique de leurs origines, la capacité de fondre des contradictions ou de les situer hors d'atteinte de la politique. Les trois espèces naufragées les plus notables étaient, tout d'abord, les emblèmes féminins incarnés dans les vierges, les sorcières et les reines ; ensuite, les épouvantails du fleuve, de la forêt et de la montagne; enfin, l'indien d'antan. Bien 
qu'apparemment on ait pu les considérer comme des entités inscrites en des moments déterminés, dans la profondeur des structures il s'agissait de fa ons de codifier une série de relations qui étaient le soutien même des mondes primordiaux, comme celles qui définissaient le masculin et le féminin, le jeune et le vieux, la terre et le ciel, le cours des eaux et l'ensemencement des terres, les bienfaits et les malfaisances, les vertus et les vices. Les espèces naufragées exposées au-delà de leurs origines, utilisées en ce qu'elles représentaient de violence mythologique, témoignaient du naufrage définitif des mondes primordiaux et leur appropriation pour la colonisation violente du monde social par divers agents armés. En raison de tout cela, les espèces naufragées dont on aurait pu croire qu'il s'agissait d'entités limitées au monde religieux, au magique et au festif, qui en apparence n'auraient été que des expressions des formes les plus pures, plus sauvages et plus idylliques de la culture, s'érigèrent en une sorte de réalisation remarquable et exemplaire de la symbiose entre culture et violence qui fut présente dans les processus qui donnèrent forme à des régions comme le Moyen Magdalena au cours des dernières dizaines d'années.

\subsection{Les emblèmes féminins}

Dans le monde originaire de la bananeraie les emblèmes féminins revêtaient une puissance liée à la fertilité de la nature, à l'attraction et au rejet des êtres, la protection et la déprotection des esprits. Mais dans la mesure où le monde originaire de la bananeraie cédait devant les mondes primordiaux gouvernés par les cultures et les industries, avec ce que cela supposait de démarcation progressive entre le naturel et le non naturel, le terrestre et l'ultra-terrestre, le magique et le religieux, ces espèces sont passées de la condition de puissances immanentes à la nature à celle d'entités anthropomorphisées qui dorénavant devraient traverser le monde dans des processions de croyants (la Vierge), des bandes de journaliers (la Sorcière) et des fêtes populaires (la Reine) en prétendant de cette façon corriger les profondes contradictions sociales, économiques et politiques apparues après leur expulsion de la bananeraie. En effet, alors que l'ancienne bananeraie avait eu pour principales vicissitudes la survie des êtres humains, la domestication des espèces et l'intempérance de la nature, le monde des mines et des cultures resta exposé au caractère problématique de la propriété de la terre, de la fertilité des sols, de la rentabilité des produits, du retour du travail humain investi, du soutien de la progéniture, l'accumulation des excédents et de la reproduction de la bourgade primordiale. C'est alors que la nature indifférenciée d'antan, devint soumise à la différenciation que lui imprimerait la propriété, le travail et le capital dont les contradictions furent traduites en péchés. Ainsi, la luxure, la gourmandise, l'avarice, l'envie, la paresse, la colère et l'orgueil qui étaient impensables dans la bananeraie, étaient plus que patents dans le monde des cultures et des industries. Les péchés nés suite à l'expulsion de la bananeraie laissèrent l'humanité du Moyen Magdalena dans le besoin et exposée aux vierges, aux sorcières et aux reines. Au milieu de la violence les vierges seraient utilisées pour la purification, les sorcières pour propager les doutes et les reines pour recouvrir l'origine dolosive des richesses.

\subsection{Les épouvantails du fleuve, de la forêt et de la montagne}

Ensuite, venaient les épouvantails du fleuve, de la forêt et de la montagne : D'un côté les entités de la bananeraie, de l'autre celles des cultures et des mines. Les premières étaient fondamentalement les esprits de la nature qui régentaient tout autant les diverses espèces végétales qu'animales, dont les hommes. Les principales entités étaient le Mohán (Personnage des eaux), la Madremonte (Mère montagne) et le Hojarasquin del Monte (Feuillage de la montagne). Quand l'organisation de l'existence dépendait de la bananeraie avec sa capacité d'harmoniser la présence du fleuve, de la forêt et de la montagne, ces esprits se manifestaient dans leur condition naturelle, prenaient les formes du paysage et chargeaient sur eux les apparences, les sons et les odeurs de la forêt. Dans ce sens, il s'agissait d'entités mythiques. Toutefois, avec l'intensification de la colonisation, la progression de la frontière agricole, ces entités prirent toujours plus des formes humaines confrontant les forces qui imposaient un monde de cultures et d'industries et tentant de restituer, ou tout au moins d'y maintenir, une partie de l'ordre primitif. L'église, décidée à prendre le monopole du monde cultivé, qu'elle entendait comme un ordre parfait, comme le démontre la profusion d'images du Royaume des cieux matérialisé par une graine, une plante, une ère, une vigne, un champ de blé, en général 


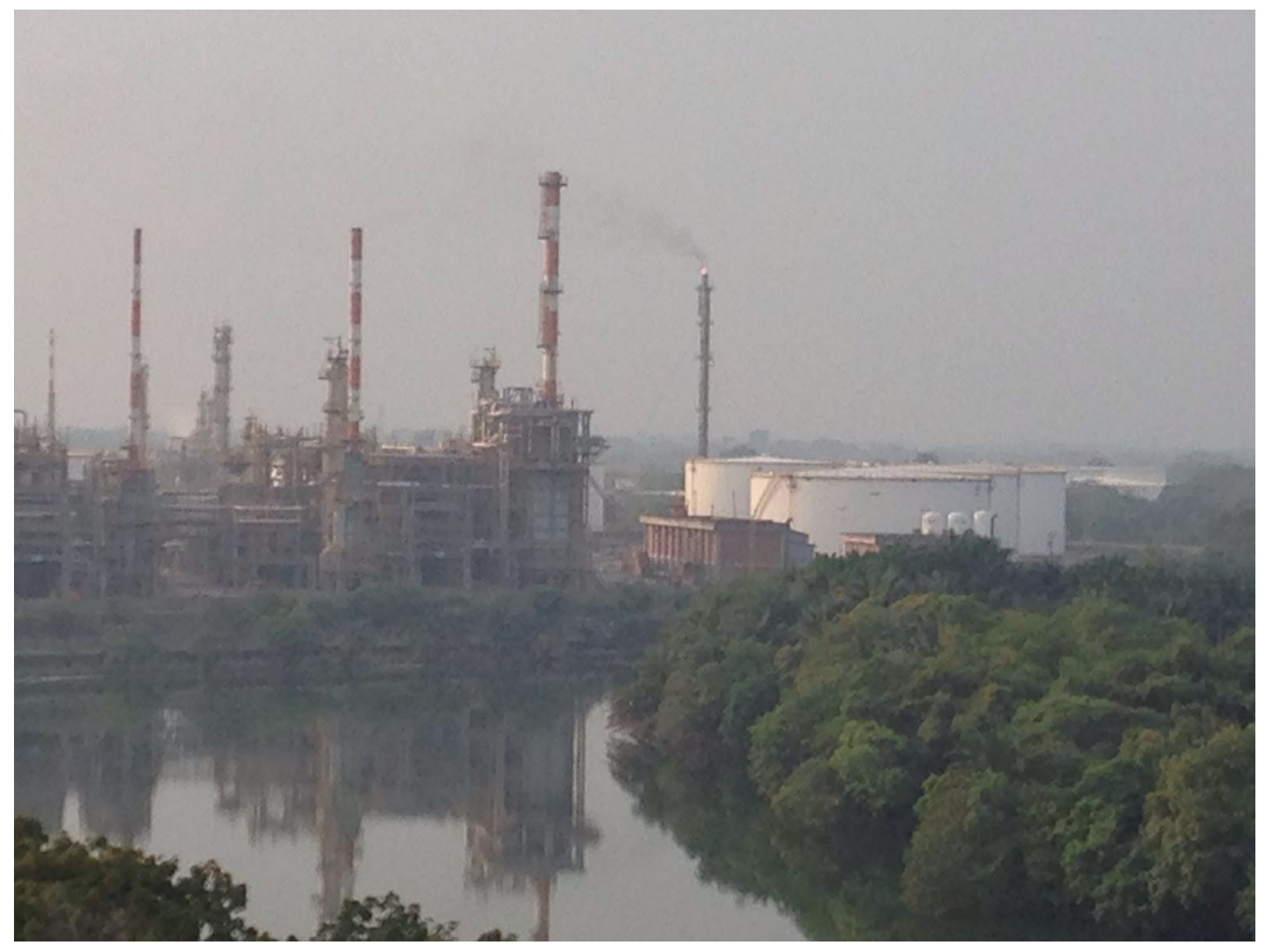

Imagen 4. Les rives du Magdalena sur Yondó (Antioquia).

une culture, a confronté ces entités primordiales avec deux figures fondamentales : la Virgen del Carmen et San Isidro Labrador — qui d'une manière ou de l'autre se firent au monopole chamanique sur les cycles de la campagne et les existences des cultures-. Alors, les entités de la bananeraie furent condamnées à errer dans le monde cultivé, exposées aux effets du tabac et de l'aguardiente qui seraient en même temps leur palliatif et leur contraire. Ce fut de cette fa on qu'elles furent vues le long des chemins par les armées des guerres civiles les convertissant même en objet de conscription, en général du côté du libéralisme. Une mythologie violentée ou une violence mythologisée qui n'était pas autre chose que la forme prise par un monde primordial allant vers l'effondrement. De toute manière, quand les cultures se sont imposées elles ont rélégué le Mohán, la Madremonte et le Hojarasquín aux ultimes réduits des forêts sur le fleuve où l'on n'entendrait plus parler d'eux que de temps à autre suite à l'une de toutes ces tragédies hivernales apportées par les fleuves grossis qui descendent des cordillères.

A la différence des entités de la bananeraie, inscrites dans le monde mythique, les entités de la mine et de la culture l'étaient dans le transit vers le monde historique : elles surgirent d'épisodes situés lors de la conquête espagnole, des guerres d'indépendance, des processus de colonisation paysanne, de l'imposition d'un régime d'haciendas, de l'apparition de l'agriculture commerciale et des guerres civiles dans le bassin du Moyen Magdalena. La première des entités de la mine et de la culture fut la Patasola (unijambiste), l'âme en peine d'une femme qui, surprise par son mari dans un acte d'infidélité vit comment l'offensé lui coupait une jambe et la jetait dans la forêt pour purger ses péchés. Venait aussi la Madredeagua (Mère de l'eau), l'âme en peine d'une femme espagnole qui, punie par son père pour ses amours avec un indien caraïbe vit comment les enfants qu'elle eut avec 


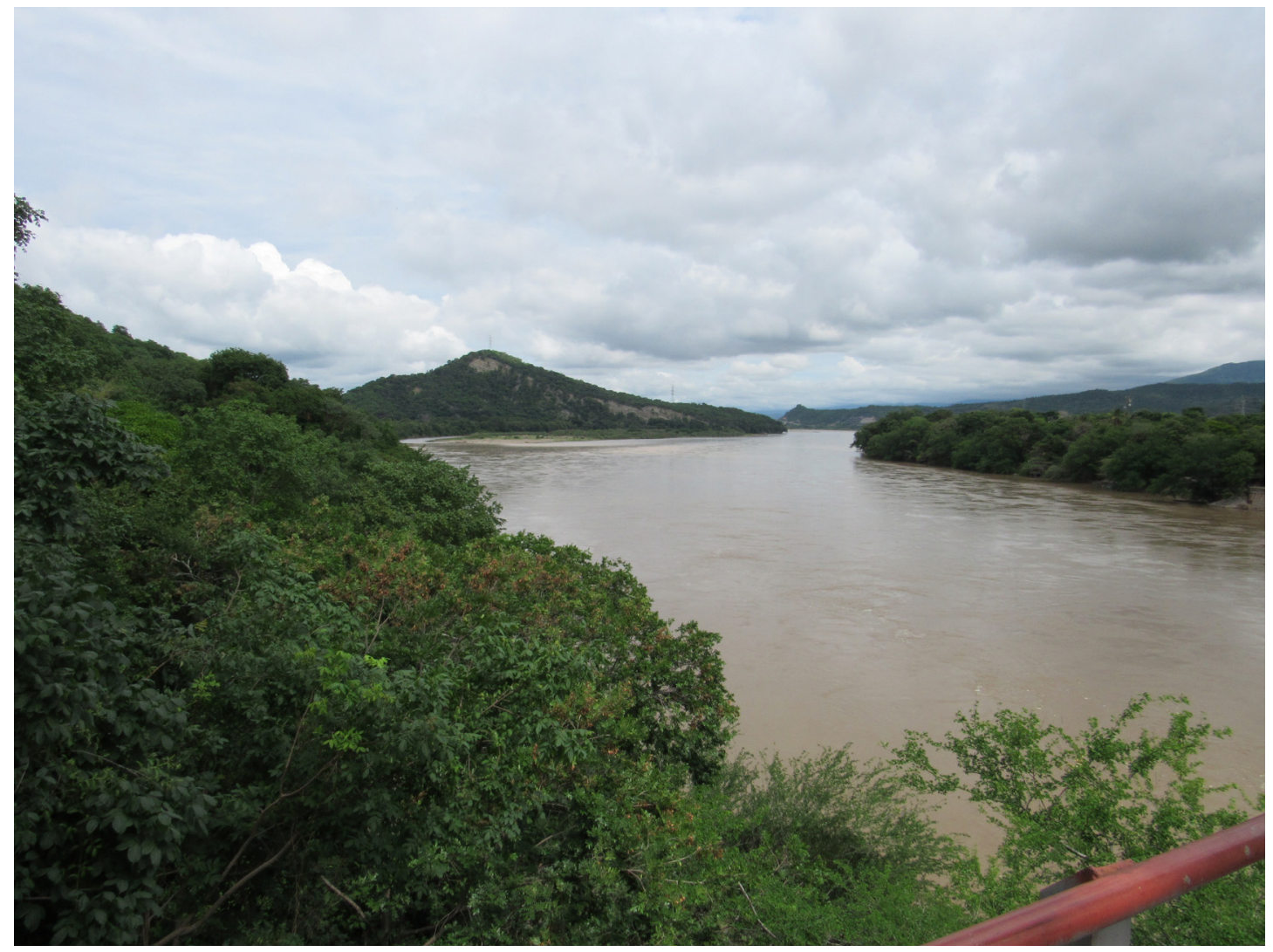

Imagen 5. Les rives du Magdalena sur Yondó (Antioquia).

lui furent jetés dans le fleuve, où elle se jeta pour tenter de leur sauver la vie mais sans y parvenir. La Llorona (Pleureuse) était l'âme en peine d'une femme d'antan qui, croyant son mari mort, un militaire atrabilaire qui était parti avec sa troupe lors d'une guerre civile, avait eu des amours avec un jeune soldat dont elle eut deux enfants qui moururent noyés quand elle chercha à fuir lorsqu'elle apprit que finalement son mari n'était pas mort. La Candileja (petit caleil ou feu follet) étaient trois feux éternels qui erraient de par le monde, les âmes en peine d'une grand-mère et de ses petits-fils malélevés, pendant que leurs parents cherchaient du travail dans les plantations de tabac. Plus bas dans la liste des épouvantails du moyen bassin du Magdalena, étaient ces entités qui furent dans leurs vies des êtres humains qui se consacraient à des travaux spécifiques mais qui, ayant désobéi à une norme supérieure ou principale, en général de contenu religieux, furent condamnés à purger des peines perpétuelles sur terre : le Pescador (pêcheur), le Cazador (chasseur), le Curé sans tête. Tous ces fantômes, parmi beaucoup d'autres, étaient surtout présents dans les plantations, terrorisant les paysans dissolus, les femmes de mauvaise vie et les patrons sans pitié.

Pour résumer, les épouvantails du fleuve, de la forêt et de la montagne n'étaient pas des entités constitutives du monde primordial mais elles apparurent avec les incertitudes, les vicissitudes et les contradictions propres du confinement de la bananeraie et de l'expansion des cultures, dont la fragilité de la fidélité des époux, l'autoritarisme extrême du père, l'obéissance aveugle des enfants, les intrigues de la propriété privée, l'exploitation du travail, la domestication des animaux, la contrainte du plaisir, I'apparition d'un sens de la localité partagée et la prolifération de personnes étranges comme celles qui venaient pour les récoltes. D'un côté, il s'agissait des vestiges qu'un monde primordial en ruines gérait encore avec des éléments mythiques, avec 
des figures étrangères à toute distinction entre le naturel et le non naturel, entre l'animal et le végétal, entre l'humain et l'animal, inscrites dans les activités quotidiennes, dans les pratiques sociales idiosyncratiques des individus. De l'autre, il s'agissait d'éléments qui, matérialisés avec les ruines d'un monde mythique, ne pouvaient être comprises à partir du monde historique sinon de manière très opaque, pour ne pas dire imparfaite, au travers du tamis de l'idéologie. Alors que dans le monde mythique les épouvantails étaient des entités naturelles, à partir du monde historique ce n'étaient plus que des entités purement sociales, inséparables des effets d'un pouvoir directif, manipulateur ou hégémonique. Précisément, le monde historique, insensible par nature à la mythique qu'il ne pouvait que revêtir comme une idéologie, ne pouvait comprendre l'efficacité symbolique des épouvantails et encore moins la manière dont celle-ci se dépla a pour s'assimiler aux agents de la violence, aux guérilleros et bandoleros, aux guérilleros de gauche puis aux paramilitaires de droite, qui, par leur présence et leurs surnoms furent les débris finaux, la poussière inerte, du monde primordial.

Au milieu des années quatre-vingt-dix, les épouvantails originaires du bassin du Moyen Magdalena étaient des espèces naufragées toujours plus étranges, seulement parfois en rapport avec des événements ponctuels, comme dans les récits qui parlaient de la présence du Mohán, dans le village d'Útica avant les inondations catastrophiques qui se produisirent au tournant du siècle. Mais ce n'était pas un hasard. Le monde dont venaient ces entités, les relations qu'elles incarnaient, les pratiques qu'elles engendraient et l'ordre moral dont elle faisait partie, s'effondra en un siècle jusqu'à l'effondrement définitif dans les vingt dernières années du siècle. Enfin, les épouvantails se refondèrent dans la littérature et dans I'histoire -les deux formes affaiblies dans lesquelles le mythe, malgré tout, se maintenait en vigueur, selon Lévi-Strauss, où I'histoire peut être rétrospective, orientée à « fonder un ordre traditionnel dans un lointain passé », ou prospective, orientée à « faire du passé la primeur d'un devenir qui commence à s'ébaucher ». Dans les villages apparus le plus récemment, ces épouvantails ancestraux furent substitués par de nouvelles entités, par des fantômes issus des accidents mortels dans les trapiches de panela, dans les mines d'émeraudes, dans les puits pétroliers, dans les haciendas de bétail et sur les grandes routes, bien qu'aucun d'eux avec des apparitions fiables et encore moins des rôles clairs -bien souvent ils font partie des fameuses légendes urbaines actuelles massifiées par Internet-.

\subsection{L'indien d'antan}

La troisième des espèces naufragées est l'indien d'antan, présente dans la toponymie, dans les anciens sites, dans les amours indiennes et chez les indiens subversifs. Le bassin du Moyen Magdalena possède une toponymie complexe issue de la confrontation dont a souffert le monde indigène depuis les temps de la conquête espagnole, en particulier par les curés doctrinaires. Les parties les plus exposées à cette ancienne confrontation dont témoigne la toponymie sont les points d'eau, les grottes ou cavernes et les hautes montagnes, qui étaient les lieux privilégiés pour les sépultures, les lieux d'adoration et les temples indigènes. Sans aucun doute, le lieu le plus important de cette confrontation fut le fleuve Magdalena même, qui aurait un rôle vertébral dans l'ensemble des structures matérielles et symboliques des anciens peuples indigènes installés dans son bassin, comme en témoignent les toponymes originels: Yuma (fleuve fidèle), commun chez les populations indigènes plus au nord, et Huacayo ou Guacacayo (fleuve des tombes), fréquent chez les populations indigènes plus au sud. Ce n'est pas un hasard si le principal personnage magico-religieux et première entité surnaturelle du fleuve, le Mohán, est présent tout le long du bassin dans le toponyme de plusieurs affluents -encore aujourd'hui, on considère que le Mohán erre à proximité des sources des rivières, le long de leurs berges inhospitalières ou à proximité des principaux ports, surtout lorsque se produisent des tragédies en raison de sécheresses d'été ou d'inondations hivernales-. A cette présence s'oppose un toponyme hispanique, celui de Magdalena, en honneur à Marie Madeleine, sœur de Marthe, femme de petite vie, disciple convaincue de Jésus et sanctifiée par l'Eglise -l'expédition espagnole de Rodrigo de Bastidas découvrit pour la première fois le fleuve, le 1er avril 1501, mais son « baptême chrétien » doit dater de la fondation de Santa Marta vers 1525-.

De toute manière, la conception mythique de la nature chez les peuples indigènes aborigènes comme la manière dont le Conquistador espagnol 
la confronterait avec ses propres conceptions magiques et religieuses furent à la base d'une toponymie qui imprima à la géographie de chaque province une sorte d'ordre spatial et temporel tout autant que moral. Ainsi, cette toponymie ne constitua pas seulement un répertoire de noms qui ne visaient qu'à donner une représentation de la nature et de la géographie pour des fins purement immédiates et instrumentales, mais que par les propres circonstances du contact colonial, cette toponymie se chargeat d'insuffler aux divers endroits une puissance dérivée d'entités naturelles ou surnaturelles, de leur transférrer des caractères propres, ce qui mena à ce que torrents, rivières et marais, collines et cordillères, plaines et forêts, acquièrent une sorte d'esprit, obtiennent une sorte de volonté, qui s'est imposée comme l'un des principes primaires du monde paysan naissant. Précisément, cette nature ou cette géographie profusément spiritualisées ne pouvaient que rester en marge au moment où l'exploitation des fleuves et rivières, des terres ou des mines apporterait avec elle de profondes contradictions et déclencherait divers conflits et violences.

L'indien d'antan migra vers le présent par le biais des guacas et guaquerias, c'est-à-dire des objets associés aux sépultures indigènes anciennes et de la preatique de chercher ces objets avec ce qu'ils portaient de mythe, magie et religion. Le guaquero se dirige vers les lieux interdits par temps couvert, croit en Dieu mais en se soumettant à la tentation du diable, ce qui convertit son travail, en une sorte de subterfuge ambigu où il n'y a pas de manière de séparer clairement ou définitivement le caractère béni ou maudit de la richesse obtenue. Cette logique de la guaca comme objet et de la guaqueria comme pratique s'est principalement développée dans ces régions où les communautés indigènes restèrent exposées à une paléo-colonisation relativement forte, comme ce fut précisément le cas sur les versants des cordillères du bassin du Moyen Magdalena. Dans cette région, la guaqueria n'est pas seulement devenue une des activités principales mais aussi une sorte d'idiosyncrasie de province qui exalterait le mineur comme ancêtre du colon ou le colon comme le continuateur de la mystique du mineur.

L'indien d'antan s'est également réfugié dans des légendes liées aux amours tragiques qui ont traversé les siècles. Parfois, il s'agissait de légendes liées à l'amour aux époques indigènes, avec l'organisation mythique du monde, l'assignation de rôles aux hommes et aux femmes, avec les unions désirées et non désirées, permises et non permises, qui restèrent consignées non seulement dans la tradition orale mais encore dans les paysages et la géographie du Moyen Magdalena -comme la montagne de Furatena-. D'autres fois encore, il s'agissait de légendes liées à l'amour au temps de la conquête, pleines d'allusions à l'ardeur des indiens dans la défense de leurs terres, de leurs richesses et de leurs femmes et aux circonstances qui, malgré cette résistance, n'empêchèrent pas la tromperie et la trahison. Avec l'amour et ses joies venait la richesse, avec le désamour et ses frustrations venait la misère. Cette présence de l'amour et de la richesse associée à l'indien d'antan sera déterminante pour revêtir de malédiction l'exploitation de la nature dans le bassin du Moyen Magdalena.

Les indiens survivaient aussi comme emblèmes de la virilité, de la guerre et de la résistance contre l'envahisseur ou contre l'oppresseur. D'un côté, l'indigène comme résistant ou subversif fit fondamentalement partie des revendications des gens des divers peuples depuis le XIXème siècle, comme une façon de réclamer la dignité des indigènes d'antan, d'en faire leurs ancêtres légitimes les rattachant à une histoire ancienne qui transcendait les Espagnols -davantage chez les populations du versant du Santander, du Boyacá et du Cundinamarca et moins chez celles de l'Antioquia et du CaldasDe l'autre, l'indigène comme résistant ou subversif devint une référence pour les groupes armés qui se formèrent à partir des années soixante, dont certains étaient effectivement influencés par des mobilisations indigènes importantes comme dans le sud du pays, d'autres davantage par la récupération intellectuelle qui se fit alors envers les peuples originaires d'Amérique. C'est ainsi, par exemple, que fut revendiquée la lutte entreprise par de grands caciques parmi lesquels il convient de citer tout particulièrement Pipatón chez les Yareguíes, Ítoco chez les Muzo-Colima, Luchaima chez les Panches et Calarcá chez les Pijaos. 


\section{Conclusion}

Comme on voit, la région du Moyen Magdalena présente une histoire complexe caractérisée par des processus sociaux, économiques, politiques et culturels marqués par d'intenses violences. L'histoire montre que la région s'est construite sur la base de plusieurs activités socioéconomiques spécifiques, sur lesquelles se sont affirmées de fortes idiosyncrasies dans chaque province ; à partir de celles-ci se sont développées des cultures singulières qui garantissaient cohésion, solidarité et identité. Elle montre également que la région s'est construite au milieu de profondes contradictions, de conflits non résolus et d'une succession de violences catastrophiques, devenues quasiment endémiques. La certitude sur l'ancienneté de la culture avec ses avantages, et l'obscurité sur la genèse de la violence avec ses maux, ont sans doute empêché de reconnaître le lien existant entre l'une et l'autre. L'opacité de ce lien est encore plus marquée dans les moments où l'exaltation de la culture de chaque province a comme correspondance une exacerbation des violences avec toutes leurs cruautés dans l'ensemble de la région. Au milieu de cette opacité s'est ébauchée comme possible lien entre la culture et la violence la présence d'une géographie d'allure agreste, la nature enfiévrée des terres chaudes, mais surtout l'existence d'un héritage ancien, celle de I'Indien d'antan, qui avec sa sauvagerie, sa bellicosité et son cannibalisme imposa la violence comme une substance de la région. Derrière cette image une histoire soumis à la dénégation : I'histoire des contradictions, conflits et violences produites pour les modèles de colonisation et les modes d'imposition du capitalisme dans le Moyen Magdalena.

La relation entre la culture et la violence est dès lors niée avec l'interposition de figures de référence qui, tout en étant considérées comme substantielles de la culture, partie prenante de ses formes essentielles ou de ses expressions primitives, sont cependant comprises comme suffisamment distantes d'elle dans l'espace et le temps. Ainsi "la vestigialisation" entraîne-t-elle "la primordialisation" du monde social, une manière de différer les contradictions et les violences des structures du présent en renvoyant leurs origines, leurs causes ou leurs manifestations aux structures du passé —ce qui explique la permanente invocation de l'Indien d'antan dans des traditions comme celles de l'Amérique latine-. De toute façon, cela mène à ce qu'au fil des générations soit assumée une relation persistante entre la culture et la violence sur la certitude différée en ces figures de référence : plus les contradictions et les violences se dissimulent et plus fréquemment est évidente la présence du fantasme produit par la mythologie. Or, cette succession de mimesis et dénis faisant appel au passé comporte différentes conséquences: depuis l'invocation de l'idiosyncrasie pour justifier, reproduire ou amplifier la violence sans réserve, jusqu'à l'imposition d'une authentique conception de l'espace et du temps, et avec cela toute une philosophie de l'histoire entichée de l'imminence de la catastrophe.

En effet, le déni de la relation structurelle entre la culture et la violence, les effets de l'enfouissement et du fantasme sont à la base d'une conception selon laquelle le monde social est prisonnier ou soumis à une malédiction ou à l'existence de faits maudits -la malédiction est un produit entre les derniers soubresauts des formes magiques et les débuts des formes religieuses, une manifestation par excellence de la transition mythologique-. Dans la région du Moyen Magdalena, la convergence d'une nature agreste abondant en ressources fabuleuses et d'hommes brutalisés par les pratiques sociales qui visent une exploitation effrénée de ces ressources, ne donne pas lieu à la génération de richesses mais, au contraire, à l'exacerbation des violences -les hommes déchaînés succombent dans leur recherche de richesses-. Cette conception du monde social est précisément le principal défi de toute tentative de réparation matérielle et symbolique aux victimes de la violence, non seulement parce qu'elle affirme que la violence n'a ni commencement ni fin précise, que les victimes sont toujours circonstancielles, et que les réparations, si légitimes ou ambitieuses soientelles, ne peuvent constituer que des palliatifs momentanés. 


\section{Bibliographie}

Abraham, N., y Torok, M. (1987). L'écorce et le noyau. Paris:

Éditions Flammarion, (Collection Champs Essais).

Alonso, M. (1997). Conflicto armado y configuración regional: el caso del Magdalena Medio. [Le conflit armé et la configuration de la région: le cas du Moyen Magdalena]. Medellín: Universidad de Antioquia, (Collection Otraparte).

Ancízar, M. (1853). Peregrinación de Alpha por las provincias del norte de la Nueva Granada en 1850 i 1851. [La pérégrination d'Alpha pour les provinces du Nord de la Nouvelle-Grenada pendant 1850 et 1851]. Bogotá: Imprenta de Echeverría Hermanos.

Archila, M. (1991). Cultura e identidad obrera. Colombia 1920-1945. [Culture et identité ouvrière. Colombie 19201945]. Bogotá: Centro de Investigación y Educación Popular-CINEP.

Archila, M., Bolívar, I., et al. (2006). Conflictos, poderes e identidades en el Magdalena Medio, 1990 - 2001. [Conflits, pouvoirs et identités dans le Moyen Magdalena, 1990-2001]. Bogotá: Centro de Investigación y Educación Popular-CINEP; Colciencias.

Benjamin, W. (¿1932? 2010). Imágenes que piensan [Les images de pensée]. Walter Benjamin. Obras. Libro IV, vol. 1. Madrid: Ediciones Abada.

Berque, A. (2009). Écoumène. Introduction à l'étude des milieux humains. París: Éditions Belin, (Collection Poche).

Bourdieu, P. (1980). Le sens pratique. Paris: Éditions de Minuit, (Collection Le Sens Commun).

(2008). «L'objectivation participante ». Esquisses algériennes. Tassadit Yacine (edt.) Paris: Éditions du Seuil (pp. 323-339). (Collection Liber).

Buenahora, G. (1970). Sangre y petróleo. [Le sang et le pétrole]. Bogotá: Editorial Colombia Nueva.

Ginzburg, C. (1989). Mythes emblèmes traces. Morphologie et histoire. Paris: Éditions Verdier, (Collection Histoire).

Horkheimer, M., y Adorno, T. W. (2010). Dialéctica de la Ilustración. Fragmentos filosóficos. [La dialectique de la raison. Fragments philosophiques]. Madrid: Editorial Trotta, (Collection Estructuras y Procesos).

IGAC-Instituto Geográfico Agustín Codazzi. (2011). Geografía de Colombia. [Géographie de la Colombie]. Bogotá: Instituto Geográfico Agustín Codazzi.

Lévi-Strauss, C. (1962). La pensée sauvage. Paris: Éditions Plon.

Murillo, A., Arcila, M. T., et al. (1993). Un mundo que se mueve como el río. Historia regional del Magdalena Medio. [Un monde bouge pour la fleuve. L'histoire de la région du Moyen Magdalena]. Bogotá: Instituto Colombiano de Antropología-ICAN; Plan Nacional de Rehabilitación -PNR.

Jay, M. (1993). Downcast eyes. The denigration of vision in twentieth-century french thought. [Les yeux baissés. Le dénigrement de la vision dans la pensée française du XXème siècle]. Los Angeles: University of California Press, (Collection History/Philosophy/Cultural Studies).

Saffray, Ch. (1869/1948). Voyage à la Nouvelle-Grenade, Le Tour du Monde. Nouveau Journal des Voyages, 24(1872), (juillet), pp. 81-144.

Sánchez, G., y Meertens, D. (1983). Bandoleros, gamonales y campesinos. El caso de la violencia en Colombia. [Bandoleros, gamonales et paysans. Le cas de la violence en Colombie]. Bogotá: El Áncora Editores.

Serna-Dimas, A. (2017). Les hommes devenus tigres. Fait colonial, mythologie nationale et violence dans le bassin moyen du fleuve Magdalena, Colombie. (Thèse de doctorat). Paris, France: L'École de Hautes Études en Sciences Sociales EHESS - Université Paris Sciences et Lettres PSL.

Solano, S. (2003). Puertos, sociedad y conflictos en el Caribe colombiano, 1850-1930. [Ports, société et conflits sur le Caraïbe colombien, 1850-1930]. Cartagena: Ministerio de Cultura y Universidad de Cartagena, (Collection Bourse pour la Recherche Culturelle Héctor Rojas Erazo).

Vargas, A. (1992). Magdalena medio santandereano: colonización y conflicto armado. [Moyen Magdalena du Département de Santander: colonisation paysanne et conflit armé]. Bogotá: Centro de Investigación y Educación Popular-CINEP, 1992, (Colección Sociedad y Conflicto). 
Vega, R. (2002). Gente muy rebelde. Protesta popular y modernización capitalista en Colombia (1909-1929). 1. Enclaves, transportes y protestas obreras. [Gens rebelles. La protestation populaire et la modernisation capitaliste en la Colombie (1909-1929). I. Enclaves, transports et protestations ouvrières]. Bogotá: Editorial Pensamiento crítico.

. (2002a). Gente muy rebelde. Protesta popular y modernización capitalista en Colombia (1909-1929). 2. Indígenas, campesinos y protestas agrarias. [Gens rebelles. La protestation populaire et la modernisation capitaliste en la Colombie (1909-1929). I. Indigènes, paysans et protestations rurales]. Bogotá: Editorial Pensamiento crítico.

Vega, R., Núñez, Á., y Pereira, A. (2009). Petróleo y protesta obrera: la Unión Sindical Obrera (USO) y los trabajadores petroleros en Colombia (1923-2008). [Pétrole et protestation ouvrière: I'Union Syndical Ouvrière (USO) et les travailleurs pétrolières en Colombie (1923-2008)]. Bogotá: Corporación Aury Sara. 